\title{
Increased expression of Sonic hedgehog restores diabetic endothelial progenitor cells and improves cardiac repair after acute myocardial infarction in diabetic mice
}

\author{
QING XIAO $^{1-3^{*}}$, XIAO-YA ZHAO ${ }^{1 *}$, RU-CHAO JIANG $^{2 *}$, XIU-HUI CHEN ${ }^{2}$, XIANG ZHU $^{2}$, KAI-FENG CHEN $^{2}$, \\ SHENG-YING CHEN ${ }^{2}$, XIAO-LING ZHANG ${ }^{4}$, YUAN QIN ${ }^{2}$, YING-HUA LIU ${ }^{2}$ and JIAN-DONG LUO ${ }^{2,3}$ \\ ${ }^{1}$ Key Laboratory of Molecular Target and Clinical Pharmacology, School of Pharmaceutical Sciences \\ and The Fifth Affiliated Hospital, Guangzhou Medical University; ${ }^{2}$ Department of Pharmacology, \\ Guangzhou Medical University, Guangzhou, Guangdong 511436; ${ }^{3}$ Guangzhou Institute of Cardiovascular Disease, \\ Guangzhou Key Laboratory of Cardiovascular Disease, The Second Affiliated Hospital, Guangzhou Medical University; \\ ${ }^{4}$ Maternal and Children Hospital of Guangdong Province, Guangzhou, Guangdong 510260, P.R. China
}

Received February 16, 2019; Accepted July 3, 2019

DOI: $10.3892 /$ ijmm.2019.4277

\begin{abstract}
Damaged endothelial progenitor cells (EPCs) are associated with poor prognosis in diabetic myocardial infarction (DMI). Our previous studies revealed that an impaired Sonic hedgehog (Shh) pathway contributes to insufficient function in diabetic EPCs; however, the roles of the Shh pathway in diabetic EPC apoptosis under basal and hypoxic/ischemic conditions remain unknown. Therefore, the present study investigated whether Shh revitalized diabetic EPCs and consequently improved the deteriorative status of DMI. For this purpose, streptozotocin injection was used in male C57/BL6 mice to induce type-1 diabetes, and diabetic EPCs were isolated from the bone marrow. Apoptosis, cell function, and protein expression were investigated in EPCs in vitro. Mouse hearts were injected with adenovirus Shh-modified diabetic EPCs
\end{abstract}

Correspondence to: Professor Jian-Dong Luo, Department of Pharmacology, Guangzhou Medical University, 195 West Dongfeng Road, Guangzhou, Guangdong 511436, P.R. China

E-mail: jiandongluo@hotmail.com

Dr Qing Xiao, Key Laboratory of Molecular Target and Clinical Pharmacology, School of Pharmaceutical Sciences and The Fifth Affiliated Hospital, Guangzhou Medical University, 195 West Dongfeng Road, Guangzhou, Guangdong 511436, P.R. China

E-mail: xiaoqingxiaomeng@163.com

*Contributed equally

Abbreviations: EPCs, endothelial progenitor cells; STZ, streptozotocin; MI, myocardial infarction; DM, diabetes mellitus; DMI, diabetic myocardial infarction; Shh, sonic hedgehog; EF, ejection fraction; FS, fractional shortening; LV, left ventricle; LVIDd, LV end-diastolic dimension; LVIDs, LV end-systolic dimension.

Key words: Sonic hedgehog pathway, endothelial progenitor cells, apoptosis, diabetic myocardial infarction, cardiac repair
(DM-EPC $^{\text {Shh }}$ ) or control DM-EPC ${ }^{\text {Null }}$ immediately after coronary artery ligation in vivo. Cardiac function, capillary numbers, fibrosis, and cell apoptosis were then detected. First, the in vitro results demonstrated that the apoptosis of diabetic EPCs was reduced following treatment with Shh protein for $24 \mathrm{~h}$, under normal or hypoxic conditions. BMI1 proto-oncogene (Bmi1), an antiapoptotic protein found in several cells, was reduced in diabetic EPCs under normal or hypoxic conditions, but was upregulated after Shh protein stimulation. When Bmil-siRNA was administered, the antiapoptotic effect of Shh protein was significantly reversed. In addition, p53, a Bmil-targeted gene, was demonstrated to mediate the antiapoptotic effect of the Shh/Bmil pathway in diabetic EPCs. The Shh/Bmi1/p53 axis also enhanced the diabetic EPC function. In vivo, Shh-modified diabetic EPCs exhibited increased EPC retention and decreased apoptosis at 3 days post-DMI. At 14 days post-DMI, these cells presented enhanced capillary density, reduced myocardial fibrosis and improved cardiac function. In conclusion, the present results demonstrated that the Shh pathway restored diabetic EPCs through the Shh/Bmi1/p53 axis, suppressed myocardial apoptosis and improved myocardial angiogenesis, thus reducing cardiac fibrosis and finally restoring myocardial repair and cardiac function in DMI. Thus, the Shh pathway may serve as a potential target for autologous cell therapy in diabetic myocardial ischemia.

\section{Introduction}

Individuals with diabetes often suffer from coronary artery diseases that contribute to their morbidity or mortality (1). The high incidence rate and unfavorable prognosis for patients with diabetes who develop coronary artery disease are associated with the diabetes-mediated impairment of angiogenesis $(1,2)$. Inhibited angiogenesis contributes to the impaired coronary collateral vessel formation and cardiac repair in patients with diabetes (3).

Accumulating evidence suggests that bone marrow-derived endothelial progenitor cells (EPCs) contribute to vascular 
repair. Preclinical and clinical studies have confirmed that EPCs improve heart function and delay cardiac remodeling after ischemic damage, by reducing fibrosis and increasing angiogenesis; in addition, autologous EPC treatment prevents immune rejection $(4,5)$. However, diabetic EPCs are insufficient in function and survival (6), thus limiting the self-repair capability of diabetic myocardial infarction (DMI) (7) and hindering autologous cell therapy (8). Effective methods of restoring diabetic EPCs to improve their angiogenic capability may be required to maximize the benefits of autologous stem cell therapy.

Hedgehog proteins are well-known morphogens that have critical roles in several tissues during embryonic and postnatal development and in adult life. The hedgehog protein family comprises Desert hedgehog, Indian hedgehog and Sonic hedgehog (Shh) (9). The Shh signal has been studied and characterized extensively during embryogenesis, tissue regeneration and repair after severe injury. This pathway occurs when the Shh protein interacts with its receptor patched 1, removing the inhibition of another Shh pathway receptor, the smoothened frizzled class receptor (Smo), and activating the transcription factor GLI family zinc finger (Gli), which induces the expression of downstream target genes, including Gli1 itself, resulting in various cellular activities (10-14). Our laboratory has recently demonstrated that the Shh pathway activity is remarkably reduced in diabetic EPCs, and that activation of the Shh pathway with the Smo receptor agonist SAG improves the function of diabetic EPCs (15). However, the Shh pathway in diabetic EPC survival or apoptosis remains poorly understood. In addition, the efficacy of EPC therapy for ischemic diseases is compromised by the poor survival of these cells under ischemic conditions. Hence, the present study examined the effect of the Shh pathway on diabetic EPC apoptosis under hypoxic conditions.

In specific, the present study investigated the effect of Shh upregulation on diabetic EPC apoptosis when transplanted into the ischemic hearts of diabetic mice, the EPC repair capability and cardiac function of diabetic mice with myocardial infarction (MI). In addition, in vitro experiments were performed to investigate the effects and molecular mechanism of Shh on diabetic EPC apoptosis under basal or hypoxic conditions.

\section{Materials and methods}

Type-1 diabetic mouse model. This study was conducted in accordance with the recommendations of the Institutional Animal Ethics Committee of Guangzhou Medical University (Guangzhou, China). The protocol was approved by the Institutional Animal Ethics Committee of Guangzhou Medical University.

The experiments were performed on healthy adult male C57/B6 mice (weight, 20 2 g; age, 6-8 weeks) obtained from Guangdong Medical Laboratory Animal Center (Foshan, China). The animals were housed in a pathogen-free environment, in a 12-h light/dark cycle, and given access to food and water ad libitum. The animals were given 2 weeks to acclimate prior to the experiments.

The MI model was established as previously described (13). Mice were injected intraperitoneally with streptozotocin (STZ; 45 mg/kg; Sigma-Aldrich; Merck KGaA) dissolved in sterile citrate buffer $(0.05 \mathrm{~mol} / \mathrm{l}$ sodium citrate, $\mathrm{pH} 4.5)$. STZ or citrate buffer (vehicle control) was administered daily for 5 consecutive days during the first week of the study. Blood samples were collected from the vena caudalis. Whole blood glucose levels were measured using the glucose analyzer One Touch Ultra Mini Blood Glucose Monitoring System (Johnson \& Johnson), and mice with a blood glucose level $\geq 16.7 \mathrm{mmol} / 1$ were considered diabetic. A total of 83 mice were established as type-1 diabetic models, and 22 mice were used as vehicle controls.

Bone marrow (BM) EPC culture and drug treatment. Human umbilical vein endothelial cells (HUVECs; American Type Culture Collection) were used as a positive control in the characterization of the EPCs, and the HUVECs were supplied by another team from our lab. EPCs were generated from $\mathrm{BM}$ mononuclear cells (MNCs), as previously described (15). In brief, the BM was flushed out from tibias and femurs, and BM-derived MNCs were isolated by density gradient centrifugation using Histopaque 1083 (Sigma-Aldrich; Merck $\mathrm{KGaA}$ ) and resuspended. BM-MNCs isolated from mice were counted and plated $\left(1 \times 10^{6}\right.$ cells/well) on fibronectin-coated 24-well plates (BD Biosciences) and then grown in endothelial cell basal medium-2 (EBM-2) supplemented with 5\% fetal calf serum (FCS) containing EPC growth cytokine cocktail [hydrocortisone, human basic fibroblast growth factor-B, vascular endothelial growth factor (VEGF), R3-insullin-like growth factor-1, ascorbic acid, human epidermal growth factor and gentamicin sulfate-amphotericin; all from Lonza Group Ltd.]. After 3 days in culture, non-adherent cells were removed, and fresh endothelial cell growth medium-2 (EGM-2; EBM-2 plus 5\% FCS and growth factor cocktail) was added every two days. All cells used in molecular assays were performed after day 7 . Shh protein $(0.5 \mu \mathrm{g} / \mathrm{ml}$; Merck KGaA), p53 agonist Tenovin-1 (10 $\mu \mathrm{M}$; Selleck Chemicals) or antioxidant Tempol $(0.5 \mathrm{mM}$; Merck KGaA) were administered for $24 \mathrm{~h}$. BMI1 proto-oncogene (Bmil)-targeting small interfering (si)RNA or Adv-Shh were applied for $48 \mathrm{~h}$. Fifty-eight mice were used for establishing the BM-derived EPCs.

Dil-conjugatedacetylatedlow density lipoprotein(Dil-acLDL) and lectin double staining. After 7 day in culture, attached EPCs were labeled with Dil-acLDL $(10 \mu \mathrm{g} / \mathrm{ml}$; Invitrogen; Thermo Fisher Scientific, Inc.) and FITC-labeled UEA-1 lectin $(10 \mu \mathrm{g} / \mathrm{ml}$; Sigma-Aldrich; Merck KGaA) for $1 \mathrm{~h}$. After washing with PBS three times, cells were observed under an inverted fluorescent microscope (Nikon Corporation). Cells demonstrating double-positive fluorescence of Dil-acLDL and lectin were identified as differentiating EPCs. EPCs from one mouse were used for fluorescence staining.

Immunofluorescence staining of CD31 and CD34. After 7 days in culture, attached EPCs were fixed by $4 \%$ paraformaldehyde for $10 \mathrm{~min}$ at room temperature (RT). After washing with PBS three times, cells were stained with anti-CD31 antibody (cat. no. 550274; 1:100; BD Biosciences) or anti-CD34 antibody (cat. no. ab81289; 1:100; Abcam) at $4{ }^{\circ} \mathrm{C}$ overnight. Next, the cells were incubated with Dylight 488-conjugated goat anti-rat secondary antibody (cat. no. A23220; 1:500; Abbkine Scientific, Co., Ltd.) or Dylight 594-conjugated 
goat anti-rabbit secondary antibody (cat. no. A23420; 1:500; Abbkine Scientific, Co., Ltd.) for $1 \mathrm{~h}$ at RT. Nuclei were counterstained with DAPI $(10 \mu \mathrm{g} / \mathrm{ml}$; Beyotime Institute of Biotechnology), and cells were examined with a fluorescent microscope (Nikon Corporation).

Hypoxic treatment. The EPCs were divided into control and hypoxia groups. In the hypoxia groups, the culture medium was changed into EBM-2, deprived of 5\% FCS and EPC growth cytokine cocktail. Then, the culture dishes were put into a hypoxia chamber (Billups-Rothenberg, Inc.), flushed with a gas mixture of $1 \% \mathrm{O}_{2}, 5 \% \mathrm{CO}_{2}$ and $94 \% \mathrm{~N}_{2}$, and maintained at $37^{\circ} \mathrm{C}$ for 6,12 and $24 \mathrm{~h}$. Oxygen concentration was measured with an oxygen analyzer (Billups-Rothenberg, Inc.). Hypoxic culture for $12 \mathrm{~h}$ was selected as the optimum analysis timepoint (Fig. S1). EPCs from 12 mice were used for hypoxic treatment.

Cell migration and tube formation assays. For migration, EPCs $\left(3.75 \times 10^{4}\right.$ cells) were placed into the upper compartment of Boyden chambers (Chemicon; Thermo Fisher Scientific, Inc.). VEGF (50 ng/ml; R\&D Systems, Inc.) and stromal cell-derived factor-1 (100 ng/ml; R\&D Systems, Inc.) were added in the lower compartment. The medium in the upper and lower compartments was serum-free EBM-2. After $16 \mathrm{~h}$, the EPCs which migrated across the membrane were counted under an inverted light microscope (Nikon Corporation), quantified and averaged by examining 5 random microscopic fields (magnification, x100). For tube formation assay, 48-well plates were coated with growth factor-reduced Matrigel (150 $\mu \mathrm{l}$; Corning, Inc.). After 7 days in culture, BM-derived EPCs $\left(1 \times 10^{5}\right.$ cells) were plated in $400 \mu \mathrm{l}$ EGM-2 medium and incubated at $37^{\circ} \mathrm{C}$ with $5 \% \mathrm{CO}_{2}$ for $16 \mathrm{~h}$. Tube formation was counted in 4 random fields at $x 40$ magnification, with a Nikon 2000 anatomical lens (15). EPCs from eight mice were used for analysis of migration and tube formation.

Transfection with Bmil-siRNA. siRNA against the mouse Bmil gene (GGACATTGCCTACATTTAT; Guangzhou RiboBio Co., Ltd.) was transiently transfected into cells using Hiperfect transfection reagent (Qiagen $\mathrm{GmbH}$ ), according to the method previously published (16). Briefly, the siRNA $(60 \mathrm{nM})$ was diluted in serum-free EBM-2, then Hiperfect transfection reagent was added to the diluted siRNA, mixed by vortexing, and allowed to form complexes for 5-10 min at RT. The complexes were then added drop-wise onto the cells for $6 \mathrm{~h}$, after which the media were replaced with normal growth media. Non-targeting siRNA was used as negative control (Guangzhou RiboBio Co., Ltd.). At 48 h post-transfection, the cells were used for subsequent experiments.

Shh gene transfer of EPCs. To upregulate the Shh expression in EPCs, recombinant adenovirus encoding mouse Shh (cat. no. 20160722003) or the control adenovirus (cat. no. CV0001) was used (Shandong Vigene Biosciences). Ex vivo gene transfer studies were conducted as described previously (17), with minor modifications. Briefly, replication incompetent adenoviral vectors, driven by a cytomegalovirus promoter, were used to deliver Shh (Adv-Shh) or control adenovirus (Adv-Null) to isolated EPCs in EGM-2 medium [multiplicity of infection (MOI), 250] for $12 \mathrm{~h}$. EPCs were used $48 \mathrm{~h}$ after the initial infection. EPCs from 50 mice were used for gene transfer.

MI model and EPC transplantation. MI was performed as previously described (13). Adult male C57/B6 mice (12 weeks of diabetes) were anaesthetized by an intraperitoneal injection of sodium pentobarbital $(50 \mathrm{mg} / \mathrm{kg})$ and artificially ventilated with a respirator. To provide analgesia, buprenorphine $(0.1 \mathrm{mg} / \mathrm{kg})$ was injected subcutaneously immediately prior to the operation, and subsequently administered every $8 \mathrm{~h}$ for the next $48 \mathrm{~h}$. After administration of the anesthetic, 7-10 min were allowed for it to take effect. The depth of general anesthesia was assessed by pinching the toe, tail or ear of the animal. Any reaction from the mouse indicated that the anesthesia was too light and that additional anesthetic agent should be given. Mice were subjected to either ligation of the left anterior descending coronary artery or to sham operation with an 8-0 suture needle. Immediately after coronary artery ligation, $2 \times 10^{5}$ EPCs were injected at three sites per mouse heart along the anterior and posterior left ventricle (LV) wall of infarct zone. PBS was used as a vehicle control, because the EPCs were suspended in PBS in this experiment. Forty mice were used for MI models, and EPCs from eight mice were used for transplantation.

CM-Dil staining for EPC retention. EPCs $\left(1 \times 10^{6}\right)$ were stained in $1 \mathrm{ml}$ M199 medium (Invitrogen; Thermo Fisher Scientific, Inc.) containing $4 \mathrm{mg} / \mathrm{ml} \mathrm{CM}$-Dil dye (chloromethyl-Dil; Invitrogen; Thermo Fisher Scientific, Inc.) for $15 \mathrm{~min}$ at $37^{\circ} \mathrm{C}$, then the stained EPCs $\left(2 \times 10^{5}\right)$ were injected in the ischemic myocardium. After 3 days of MI, the fresh myocardium was collected and tissue OCT-freeze medium was injected into the LV. After freezing the tissue, the myocardium was cut into serial frozen sections from the ligation point to the apex of myocardium, every $100 \mu \mathrm{m}$. The frozen sections were observed using a fluorescent microscope (Nikon Corporation; magnification, x40). The average fluorescence of the serial frozen sections represented the result of one sample. EPCs from three mice were used for CM-Dil staining, and 15 mice were used for the EPC retention assay.

Terminal deoxynucleotidyl transferase-mediated dUTP nick end-labeling (TUNEL) staining in myocardium in vivo and in vitro. At 3 days post-MI, cell survival in the myocardium was determined by TUNEL staining on $5 \mu \mathrm{m}$ thick frozen sections, or in vitro in EPCs, as per the manufacturer's instructions (Cell death detection assay; Roche Diagnostics). DAPI $(10 \mu \mathrm{g} / \mathrm{ml}$; Beyotime Institute of Biotechnology) staining was used to count the total number of nuclei. In vivo, apoptotic cells were observed in the peri-infarct and infarct myocardium under z100 magnification, with a Nikon TI fluorescence microscope (Nikon Corporation). In vitro, five cell fields were captured randomly per sample using confocal fluorescence microscopy (Nikon A1; Nikon Corporation). Twenty mice were used for in vivo detection, and EPCs from 12 mice were used for in vitro detection.

Dihydroethidium (DHE) dye. Superoxide production was detected using DHE staining (Sigma-Aldrich; Merck KGaA). 
EPCs were fixed with $4 \%$ paraformaldehyde at $4^{\circ} \mathrm{C}$ overnight, and incubated with $10 \mu \mathrm{M}$ DHE for $45 \mathrm{~min}$ at $37^{\circ} \mathrm{C}$ in a humidified chamber in the dark. The average fluorescence intensity of the nuclei was then analyzed using Image Pro-Plus software 6.0 (Media Cybernetics, Inc.).

Immunofluorescence staining of capillary vessels. On day 14 after induction of MI, the hearts were harvested and embedded into frozen OTC. Immunofluorescence staining of frozen sections was performed as described previously (18). Tissue sections were permeabilized and stained with anti-CD31 antibody (1:50; BD Biosciences) to label the capillaries, followed by incubation with the respective secondary antibody. Nuclei were counterstained with DAPI $(10 \mu \mathrm{g} / \mathrm{ml}$; Beyotime Institute of Biotechnology), and sections were examined with a fluorescent microscope (Nikon TI; magnification, x100). The number of capillaries (CD31-positive, green) was assessed in the border zone of the infarcted myocardium. Twenty mice were used for capillary vessel analysis.

Assessment of percentage myocardial infarct and fibrosis (Masson's trichrome staining). On day 14 after induction of MI, the hearts were perfusion-fixed with $10 \%$ buffered formalin, horizontally sectioned at $0.5 \mathrm{~mm}$ thickness between the point of ligation and the apex, and then embedded in paraffin. The percentage myocardial infarct was obtained on Masson's trichrome-stained tissue sections using Image Pro-Plus software (Media Cybernetics, Inc.). The fibrosis and total LV area were measured and expressed as a final percentage myocardial infarct (19). Twenty mice were used for Masson's trichrome staining.

Echocardiography. Transthoracic two-dimensional M-mode echocardiogram was performed using Vevo 2100 (VisualSonics) equipped with $30 \mathrm{MHz}$ transducer. Echocardiographic studies were performed before (baseline) and at 14 days post-MI on mice anesthetized with a mixture of $1.5 \%$ isoflurane and oxygen $(1 \mathrm{l} / \mathrm{min})$. M-mode tracings were used to measure LV wall thickness, LV end-diastolic dimension (LVIDd) and LV end-systolic dimension (LVIDs). The mean value of three measurements was determined for each sample. Percent fractional shortening (FS) and ejection fraction (EF) were automatically calculated by the software (13). Twenty mice were used for echocardiography.

Western blot analysis. Western blot analysis was performed as previously described (20). EPCs were lysed in lysis buffer (Cell Signaling Technology, Inc.) with protease inhibitor cocktail (Merck KGaA) for $30 \mathrm{~min}$ on ice. Then the lysed liquid was collected with a cell scraper. After centrifugation for $10 \mathrm{~min}$ at $12,000 \mathrm{xg}$ at $4^{\circ} \mathrm{C}$, the supernatant was used for the detection of protein concentration with a bicinchoninic acid protein assay kit (Pierce; Thermo Fisher Scientific, Inc.). A total of $30 \mu \mathrm{g}$ of protein was loaded onto $12 \%$ SDS-PAGE and transferred to polyvinylidene fluoride membranes (EMD Millipore). After blocking in 5\% skimmed milk for $1 \mathrm{~h}$ at RT, membranes were incubated with primary antibodies against Gli1 (cat. no. ab151796; 1:1,000; Abcam), Bmil (cat. no. 5856; 1:1,000; Cell Signaling Technology, Inc.), p53 (cat. no. 2524; 1:1,000; Cell Signaling Technology, Inc.), cleaved caspase-3 (cat. no. 9664; 1:1,000; Cell Signaling Technology, Inc.) and eNOS (cat. no. 32027; 1:1,000; Cell Signaling Technology, Inc.) overnight at $4^{\circ} \mathrm{C}$. After washing with TBST (TBS/1\% Tween-20), membranes were incubated with horseradish peroxidase-conjugated secondary antibodies anti-mouse or anti-rabbit (cat. no. BS13278; 1:5,000; Bioworld Technology, Inc.) at RT for $1 \mathrm{~h}$. GAPDH (cat. no. BS60630; 1:5,000; Bioworld Technology, Inc.) was used as a loading control. Bands were visualized using a chemiluminescence kit (Cell Signaling Technology, Inc.) and X-ray films (Kodak). The band densities were quantified using the Image-J software (version 1.48u; National Institutes of Health). EPCs from 31 mice were used for western blot analysis.

Statistical analysis. All data were analyzed with the statistical software GraphPad Prism 5.0 (GraphPad Software, Inc.), and all values were expressed as means \pm SEM. Differences between two groups were analyzed using Student's unpaired t-test, and differences between three or more groups were evaluated via one-way ANOVA with Bonferroni correction. $\mathrm{P}<0.05$ was considered to indicate a statistically significant difference.

\section{Results}

Characterization of EPCs. Although EPCs are heterogeneous in nature, they possess stem cell characteristics and can be differentiated into endothelial cells. To characterize BM-derived EPCs, the expression of the stem cell marker CD34 and the endothelial cell marker CD31 was examined by immunofluorescence (Fig. 1A). Western blot analysis indicated that, similar to HUVECs, cultured EPCs expressed the endothelial marker eNOS, whereas no eNOS expression was evident in the MNCs (Fig. 1B). These data suggested that the 7 day-cultured EPCs maintained stem cell-characteristics and contained higher populations of endothelial cells than the freshly isolated MNCs. The 7 day-cultured EPCs were also confirmed by Dil-ac-LDL and FITC-lectin double staining, a previously defined characteristic of EPCs (Fig. 1C). Fig. 1D displays the growth of EPCs for 7 days. Spindle cells and colonies occurred from day 3 , several cobblestone cells appeared from day 5 , and the density of cobblestone cells increased on day 7 .

Cell apoptosis is increased and Shh pathway is impaired in diabetic EPCs under basal or hypoxic conditions. Control and diabetic EPCs were cultured for $12 \mathrm{~h}$ under hypoxic conditions, and then cell apoptosis was evaluated. The percentage of apoptotic cells (positive for TUNEL staining) was significantly higher in the diabetic group compared with the control group under basal and hypoxic conditions (Fig. 2A). Similarly, the protein expression levels of the proapoptotic cleaved caspase- 3 were significantly upregulated in the diabetic EPCs under basal or hypoxic conditions (Fig. 2B). By contrast, the expression levels of the Shh pathway proteins Shh and Gli1 were significantly decreased in the diabetic EPCs (Fig. 2C). When administered with the antioxidant Tempol $(0.5 \mathrm{mM})$, the diabetic EPCs displayed reduced reactive oxygen species (ROS) and upregulated protein levels of Shh and Gli1 (Fig. S2), implying that oxidative stress may be involved in the impaired Shh pathway. After hypoxia treatment, the protein expression 


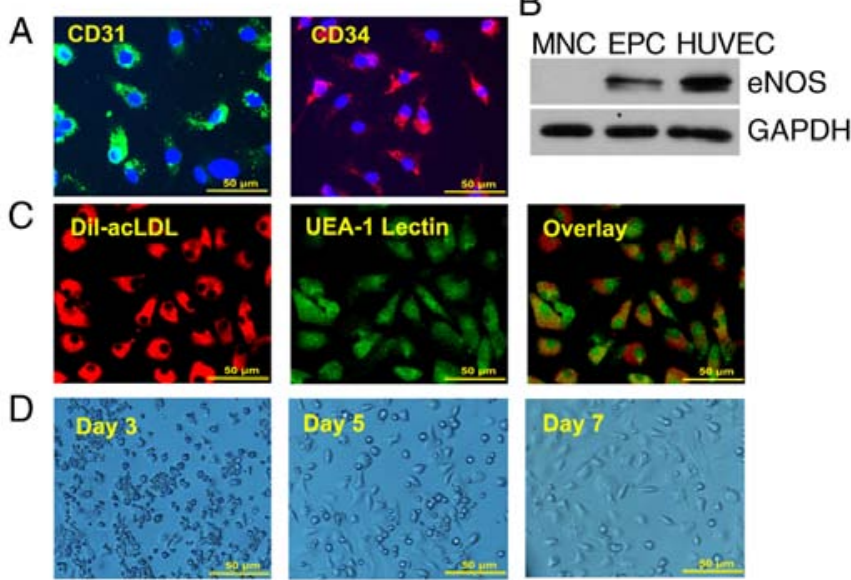

Figure 1. Characterization of endothelial progenitor cells. (A) Expression of the endothelial cell-specific marker CD31 and the stem cell-specific marker CD34 was examined in cultured EPCs (day 7) by immunofluorescent staining. (B) Expression of eNOS in freshly isolated bone marrow-derived MNCs, 7 day-cultured EPCs, and HUVECs was detected by western blotting. (C) Fluorescent imaging indicated Dil-acLDL incorporation (red) and FITC-lectin binding (green) in 7 day-cultured EPCs. (D) Morphology of cultured EPCs (days 3, 5, and 7) by phase-contrast microscopy. EPCs, endothelial progenitor cells; eNOS, endothelial nitric oxide synthase; MNCs, mononuclear cells; HUVECs, human umbilical vein endothelial cells; Dil-acLDL, Dil-conjugated acetylated low density lipoprotein

levels of Shh and Glil were significantly upregulated in the control EPCs, but were not changed in the diabetic EPCs (Fig. 2C). The present data suggested a possible link between Shh pathway downregulation and increased diabetic EPC apoptosis under basal or hypoxic conditions.

Activation of the Shh pathway in diabetic EPCs decreases apoptosis under basal or hypoxic conditions. Diabetic EPCs were stimulated with Shh protein, and cellular apoptosis was evaluated to further determine the relationship between the Shh pathway and diabetic EPC apoptosis. After treatment with the Shh protein $(0.5 \mu \mathrm{g} / \mathrm{ml})$, Gli1 protein expression levels were significantly increased, suggesting the rescue of the impaired Shh pathway (Fig. 3A). The protein expression levels of the proapoptotic protein cleaved caspase-3 were significantly reduced (Fig. 3A), and the ratio of TUNEL-positive cells was significantly decreased in the diabetic EPCs (Fig. 3B). This protection from apoptosis was also observed under hypoxic conditions. Western blot and TUNEL assays demonstrated that the Shh protein $(0.5 \mu \mathrm{g} / \mathrm{ml})$ significantly reduced the cleaved caspase- 3 protein expression levels and the ratio of TUNEL-positive cells in the diabetic EPCs under hypoxic conditions (Fig. 3). These results suggested that activation of the Shh pathway protected diabetic EPCs from cell death.

The antiapoptotic effect of Shh in diabetic EPCs is attenuated by Bmil silencing. The mechanism by which the Shh pathway may regulate apoptosis in diabetic EPC remains unknown. Bmil is a polycomb group protein that enters into the nucleus to repress gene transcription and regulate the function and viability of various types of cells (21). A potential link exists between Shh signaling and Bmilin the proliferation of cerebellar granule cell progenitors, glioma cells, and medulloblastoma brain tumor-initiating cells (22-24); however, the antiapoptotic effect of the Shh/Bmil pathway is poorly understood. In the present study, it was demonstrated that, similar to the Shh pathway, Bmil protein expression levels were significantly reduced in the diabetic EPCs under basal or hypoxic conditions, while stimulation with the Shh protein $(0.5 \mu \mathrm{g} / \mathrm{ml})$ significantly rescued the protein expression levels of Bmil (Fig. 3A). When Bmi1-siRNA was delivered in the Shh protein-stimulated diabetic EPCs, the ratio of TUNEL-positive EPCs and the protein expression levels of cleaved caspase-3 showed a reverse trend. Bmil-siRNA was continuously applied in the diabetic EPCs under hypoxic conditions; Bmil silencing also reversed the declining numbers of TUNEL-positive EPCs and the reduced protein expression levels of cleaved caspase- 3 mediated by the Shh protein stimulation (Fig. 3).

Next, the effect of the Shh/Bmi1 pathway was investigated on normal EPCs. When stimulated with the Shh protein $(0.5 \mu \mathrm{g} / \mathrm{ml})$, the protein expression levels of Gli1 and Bmil were significantly upregulated under basal and hypoxic conditions, whereas the cleaved caspase-3 levels and the ratio of TUNEL-positive EPCs were reduced under hypoxic conditions, but hardly changed under basal conditions (Fig. 4). Following Bmil silencing, the protein expression levels of Bmil were downregulated, but the levels of Gli1 were unchanged (Fig. 4A). In addition, the cleaved caspase-3 levels and the ratio of TUNEL-positive EPCs increased under basal conditions, but hardly changed under hypoxic conditions (Fig. 4). When Shh protein plus Bmil-siRNA were administered, the protein expression levels of Bmil were significantly reduced, but the levels of Gli1 were unchanged, and the cleaved caspase-3 levels and the ratio of TUNEL-positive EPCs increased under basal and hypoxic conditions, compared with the Shh stimulation alone group (Fig. 4). These data indicated that the antiapoptotic effect of the Shh/Bmil pathway was evident under basal/hypoxic conditions and under diabetic/normal conditions.

The protective effect of Shh in diabetic EPC function is attenuated by Bmil silencing. It was previously revealed that the Shh pathway is closely related to the malfunction of diabetic EPCs (15); however, the involvement of downstream Bmil is unknown. In the present study, EPC function was assessed through tube formation and cell migration assays. The results demonstrated that the stimulation of tube formation induced by the Shh protein $(0.5 \mu \mathrm{g} / \mathrm{ml})$ was significantly hindered by Bmil silencing in the diabetic EPCs. Cell migration was also substantially diminished following Bmil silencing (Fig. 5A).

The association between Shh and Bmil was also analyzed in normal EPCs. The results demonstrated that tube formation and cell migration were significantly enhanced after stimulation with the Shh protein $(0.5 \mu \mathrm{g} / \mathrm{ml})$. When Bmil-siRNA was added in the Shh protein group, the EPCs had decreased tube formation and cell migration compared with the Shh protein alone group (Fig. 5B). In addition, treatment with Bmil-siRNA in the control group also significantly reduced tube formation and cell migration (Fig. 5B). These data indicated that the Shh/Bmil pathway affected EPC function under diabetic and normal conditions.

P53 mediates the positive role of the Shh/Bmil axis in diabetic $E P C s$. The present study focused on the downstream factor 


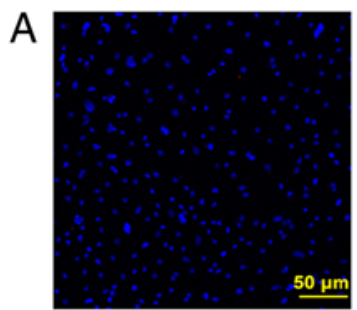

CON

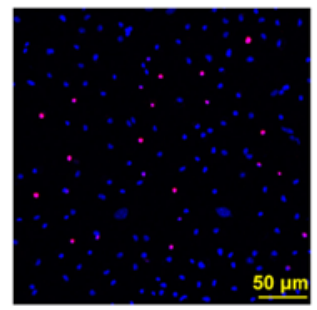

CON+Hypoxia $12 \mathrm{~h}$

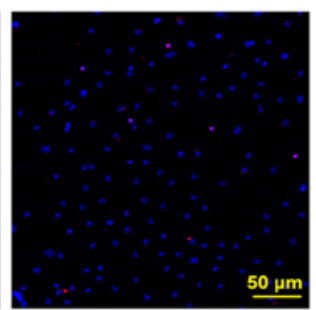

DM

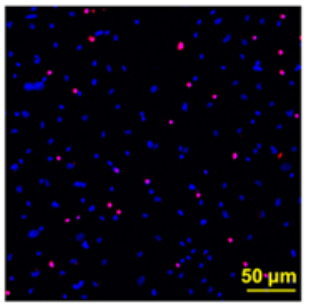

$\mathrm{DM}+\mathrm{Hypoxia} 12 \mathrm{~h}$
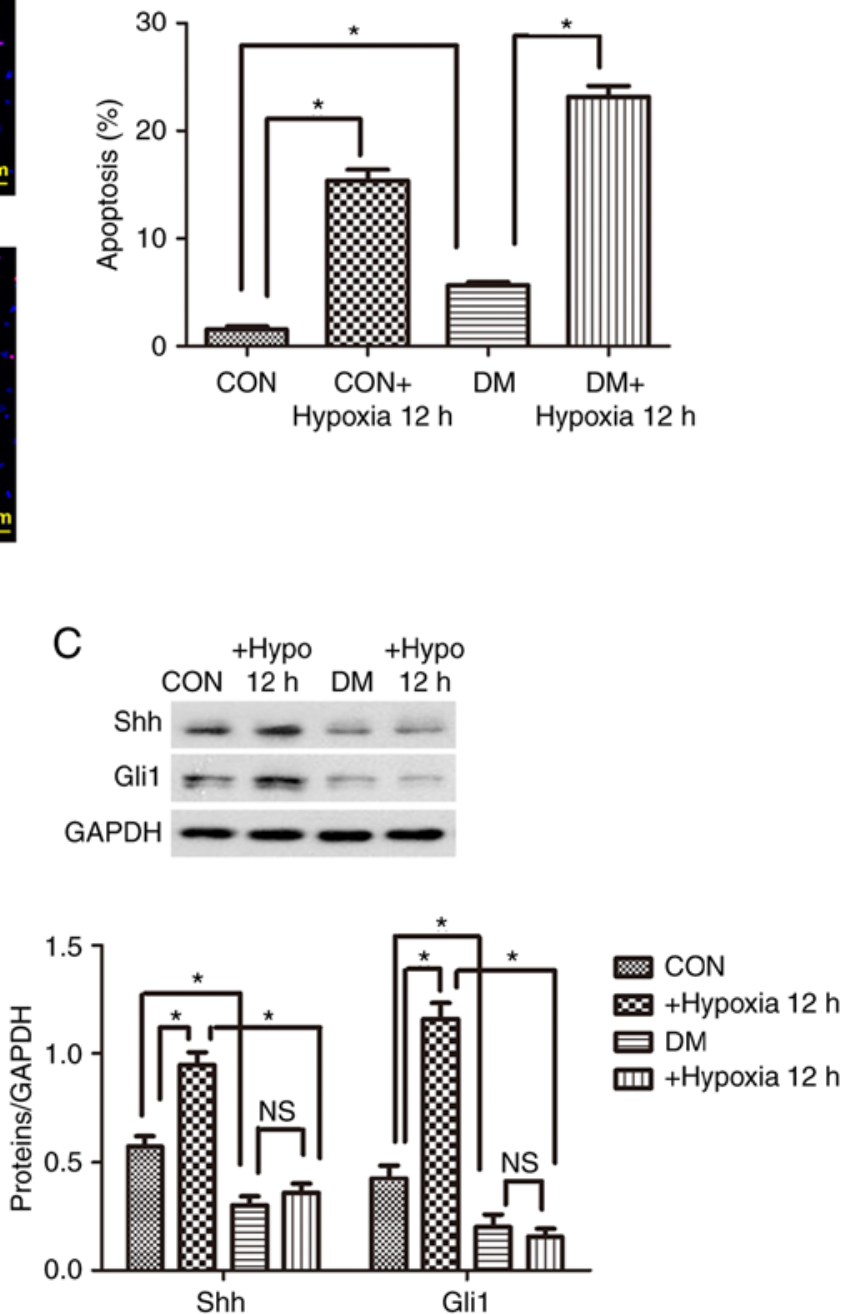

Figure 2. Cell apoptosis is increased in diabetic EPCs under basal or hypoxic conditions. Diabetic EPCs were isolated from 12-week diabetic mice and then cultured for 7 days. The 7 day-cultured EPCs were stimulated by hypoxia for $12 \mathrm{~h}$. (A) Representative images and quantitative analysis of TUNEL-positive cells (red). Nuclei were counterstained with DAPI (blue). (B) Western blot analysis of cleaved caspase-3, and of (C) Shh and Gli1 protein expression levels. Three independent experiments were performed. Values are presented as means \pm standard error of the mean. ${ }^{*} \mathrm{P} \leq 0.05$, with comparisons indicated by brackets. EPCs, endothelial progenitor cells; Shh, sonic hedgehog; Gli1, GLI family zinc finger 1; CON, control; DM, diabetes mellitus; Hypo, hypoxia; NS, not significant.

that mediates the Shh/Bmi1 axis in diabetic EPCs. p53, an important protein related to proliferation and apoptosis, was investigated. The results demonstrated that p53 was significantly activated in diabetic EPCs compared with normal EPCs (Fig. 6A); this effect was opposite to the reduced expression of Shh and Bmil in diabetic EPCs (Fig. 3). Treatment with the Shh protein significantly reduced the protein expression levels of p53 in diabetic EPCs (Fig. 6A).

When the p53 agonist Tenovin-1 $(10 \mu \mathrm{M})$ was added, the Shh protein-stimulated EPCs presented increased protein expression levels of cleaved caspase-3 (Fig. 6B) and reduced numbers of tube formation and cell migration (Fig. 6C), compared with the Shh protein group alone. By contrast, Tenovin-1 barely affected Bmi1 protein expression (Fig. 6B), whereas the treatment with Bmil-siRNA significantly reversed the Shh protein-induced p53 reduction (Fig. 6A). These results indicated that p53 was a downstream factor in the Shh/Bmil pathway.
Shh overexpression by adenoviral infection decreases apoptosis and improves the function of diabetic EPCs. To evaluate whether modifying the Shh pathway in diabetic EPCs could improve the beneficial effects of autologous stem cell therapy, the cells were infected with recombinant adenovirus overexpressing Shh or control adenovirus, and then implanted into the infarcted hearts of diabetic mice. For the infection, an MOI of 250 was used, according to a a previous study (17). To confirm the transfer efficacy, the protein expression levels of Shh and Gli1 were examined in cell lysates by western blot analysis. As shown in Fig. 7A, the protein expression levels of Shh and Gli1 were significantly higher in the Adv-Shh-infected cells compared with cells transfected with control adenovirus. These results indicated the effective gene modification of diabetic EPCs with adenovirus ex vivo, resulting in the activation of the cellular Shh pathway in diabetic EPCs.

To investigate the effect of Shh overexpression on the status of EPCs, diabetic EPCs were infected with Shh or Null 
A

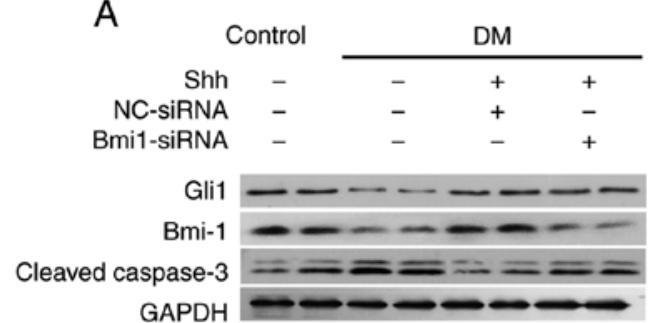

GAPDH
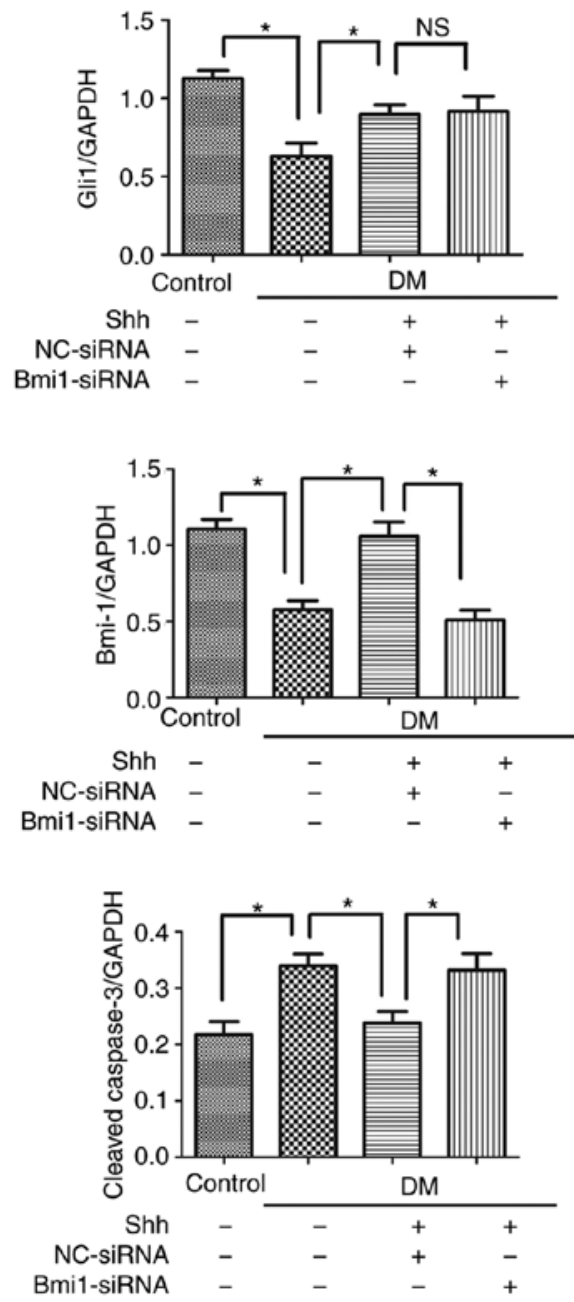

B
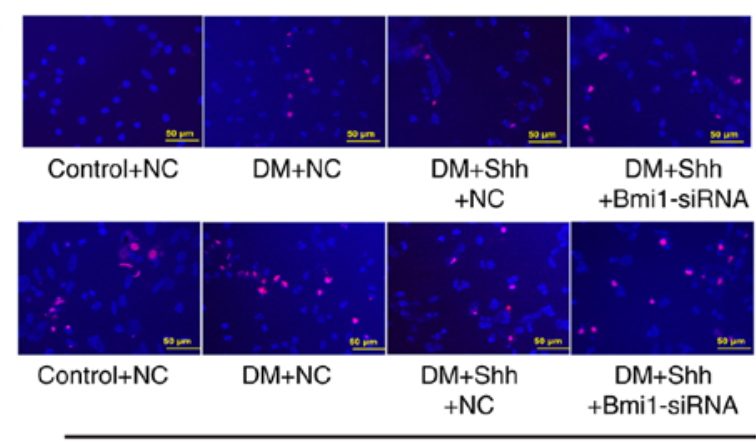

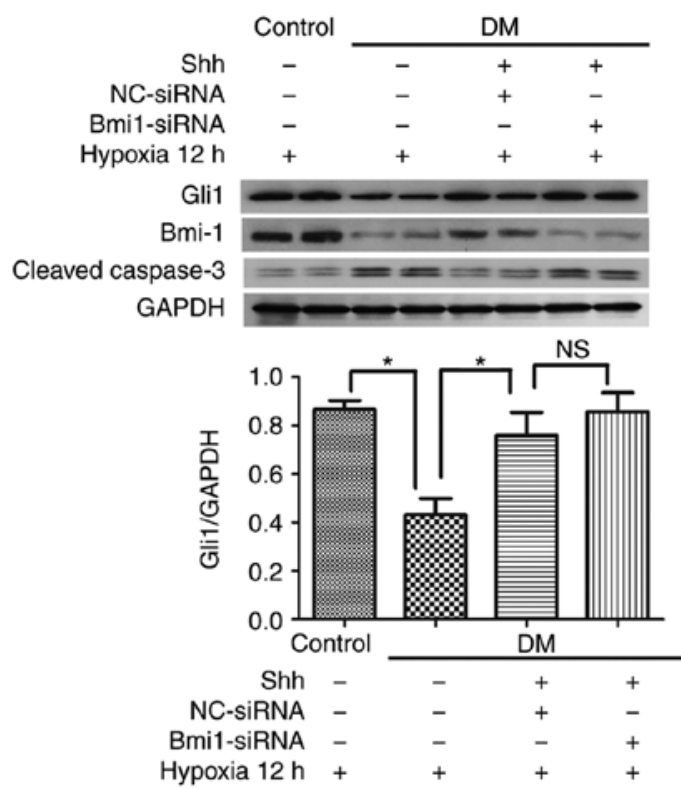

Hypoxia $12 \mathrm{~h}+\quad+\quad+$

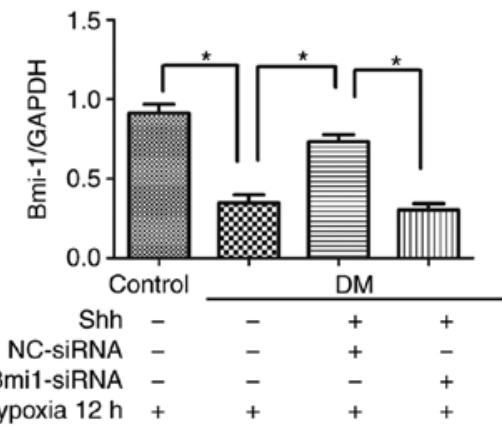

Hypoxia $12 \mathrm{~h}+\quad+\quad+$
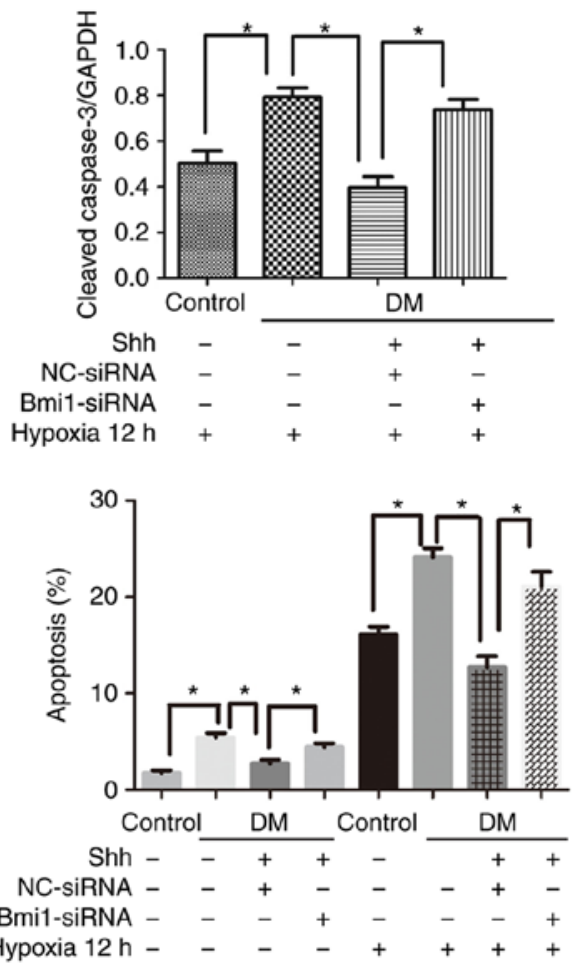

Hypoxia $12 \mathrm{~h}$

Figure 3. Bmil mediates the antiapoptotic effect of the Shh pathway in diabetic EPCs under basal or hypoxic conditions. The 7 day-cultured EPCs were transfected with Bmil-siRNA or NC-siRNA for $24 \mathrm{~h}$, and then stimulated with the Shh protein $(0.5 \mu \mathrm{g} / \mathrm{ml})$ for another $24 \mathrm{~h}$. After that, the cells were incubated under hypoxic conditions for $12 \mathrm{~h}$. (A) Western blot analysis of Gli1, Bmil and cleaved caspase-3 protein expression levels. (B) Representative images and quantitative analysis of TUNEL-positive cells (red). Nuclei were counterstained with DAPI (blue). Three independent experiments were performed. Values are presented as means \pm standard error of the mean. " $\mathrm{P} \leq 0.05$, with comparisons indicated by brackets. Bmi1, BMI1 proto-oncogene; Shh, sonic hedgehog; EPCs, endothelial progenitor cells; si, small interfering; NC, negative control; Gli1, GLI family zinc finger 1; DM, diabetes mellitus; NS, not significant. 
A
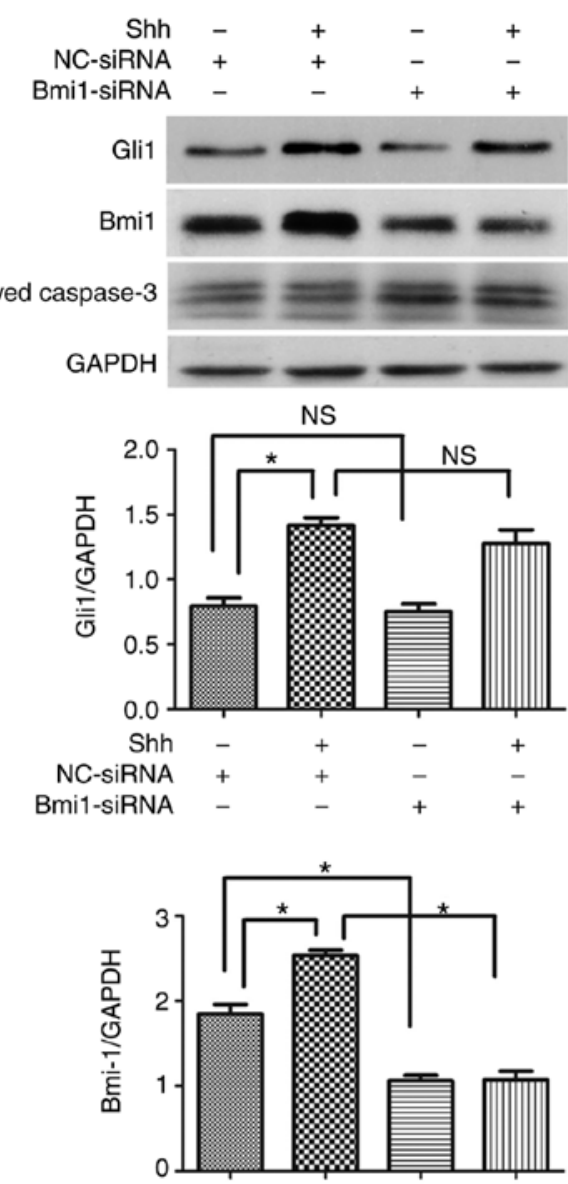

Shh

$\begin{array}{rrrrr}\text { Shh } & - & + & - & + \\ \text { NC-siRNA } & + & + & - & - \\ \text { Bmi1-siRNA } & - & - & + & +\end{array}$

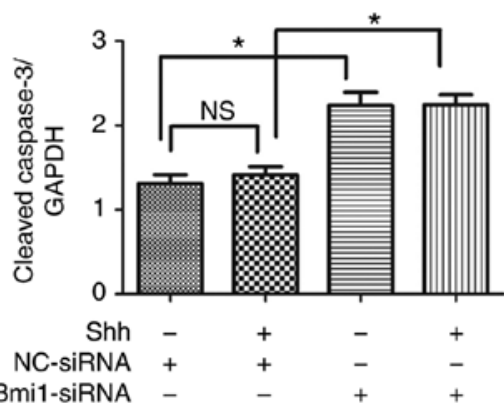

B

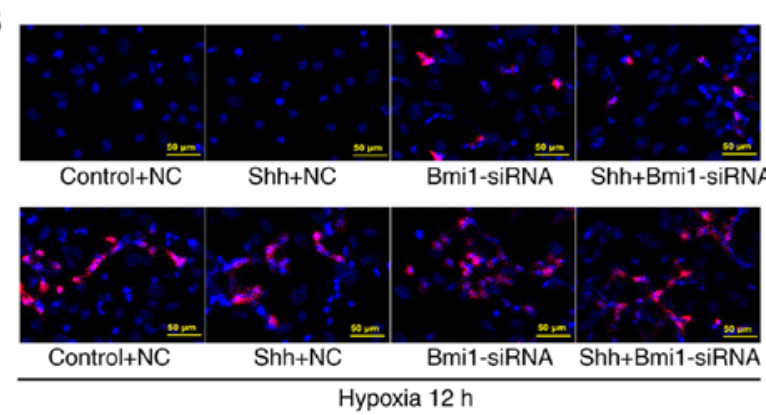

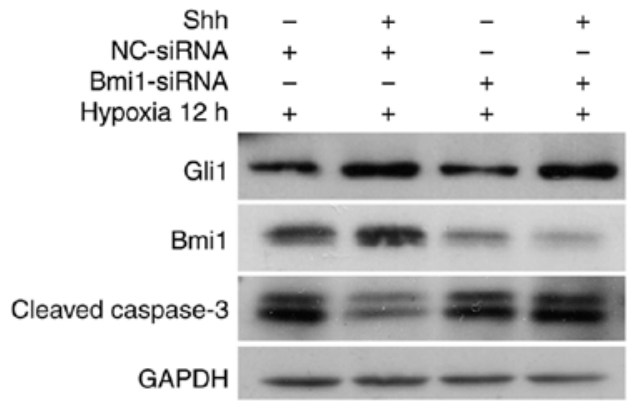

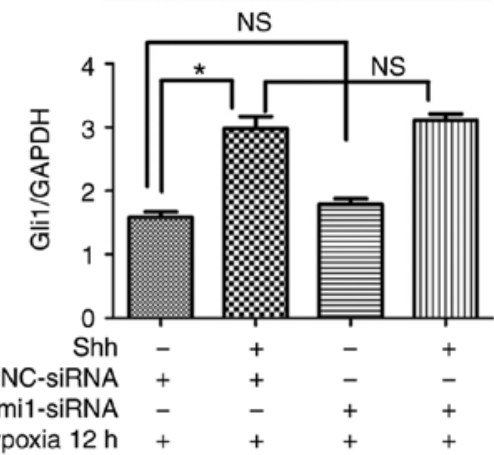

Hypoxia 12
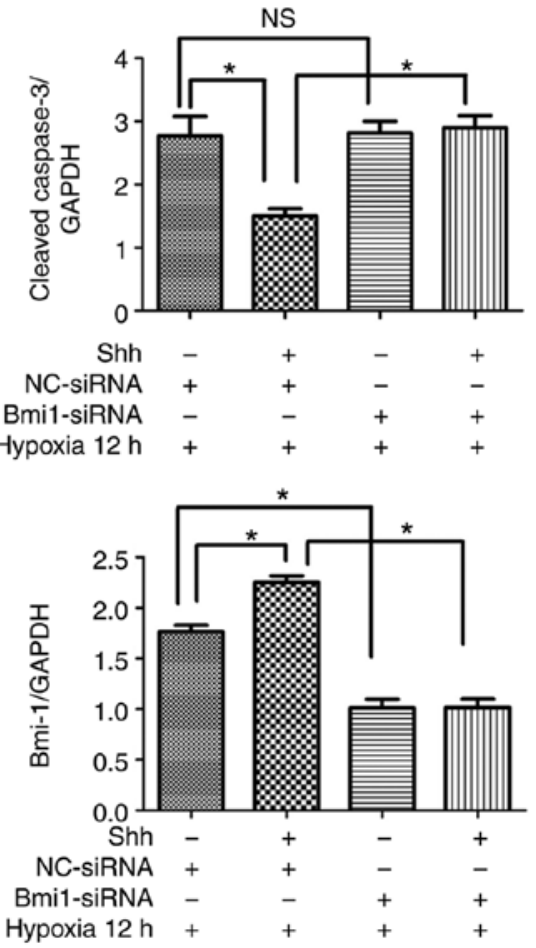

Figure 4. Bmil mediates the antiapoptotic effect of the Shh pathway in normal EPCs under hypoxic conditions. The 7 day-cultured normal EPCs were transfected with Bmil-siRNA or NC-siRNA for $24 \mathrm{~h}$, and then stimulated with the Shh protein $(0.5 \mu \mathrm{g} / \mathrm{ml})$ for another $24 \mathrm{~h}$. After that, the cells were incubated under hypoxic conditions for $12 \mathrm{~h}$. (A) Western blot analysis of Gli1, Bmil and cleaved caspase-3 protein expression levels. (B) Representative images and quantitative analysis of TUNEL-positive cells (red). Nuclei were counterstained with DAPI (blue). Three independent experiments were performed. Values are presented as means \pm standard error of the mean. "P $\leq 0.05$, with comparisons indicated by brackets. Bmil, BMI1 proto-oncogene; Shh, sonic hedgehog; EPCs, endothelial progenitor cells; si, small interfering; NC, negative control; Gli1, GLI family zinc finger 1; DM, diabetes mellitus; NS, not significant. 
A

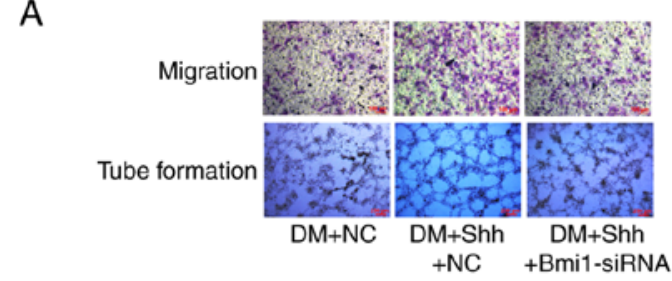

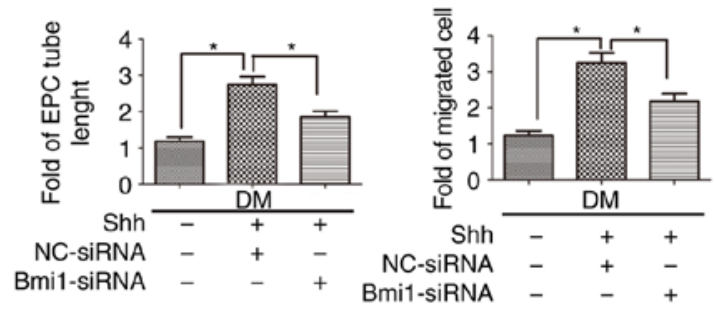

B

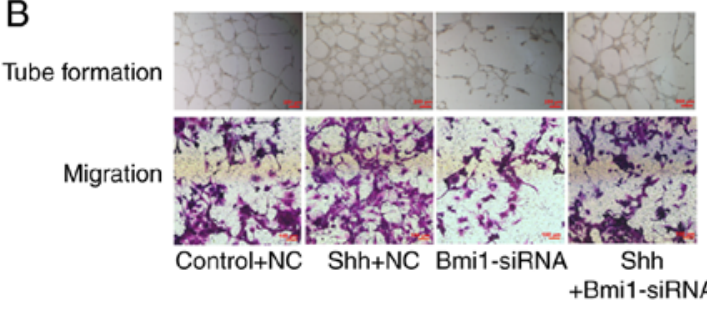

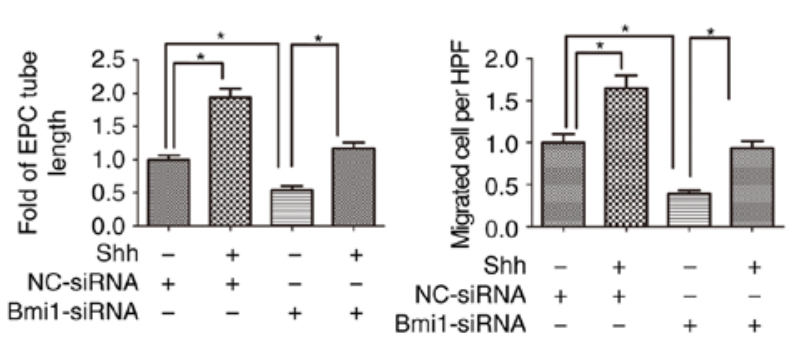

Figure 5. Bmil mediates the protective effect of Shh pathway in diabetic EPC function. The 7 day-cultured (A) diabetic EPCs and (B) normal EPCs were transfected with Bmil-siRNA or NC-siRNA for $24 \mathrm{~h}$ and then stimulated with the Shh protein $(0.5 \mu \mathrm{g} / \mathrm{ml})$ for another $24 \mathrm{~h}$. EPC function was examined by cell migration and tube formation assays. Three independent experiments were performed. Values are presented as means \pm standard error of the mean. "P $\leq 0.05$, with comparisons indicated by brackets. Bmil, BMI1 proto-oncogene; Shh, sonic hedgehog; EPC, endothelial progenitor cell; si, small interfering; $\mathrm{NC}$, negative control; DM, diabetes mellitus.

A
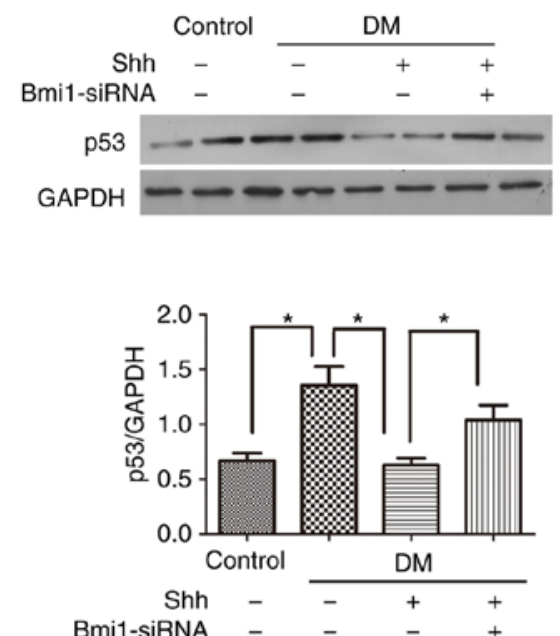

B
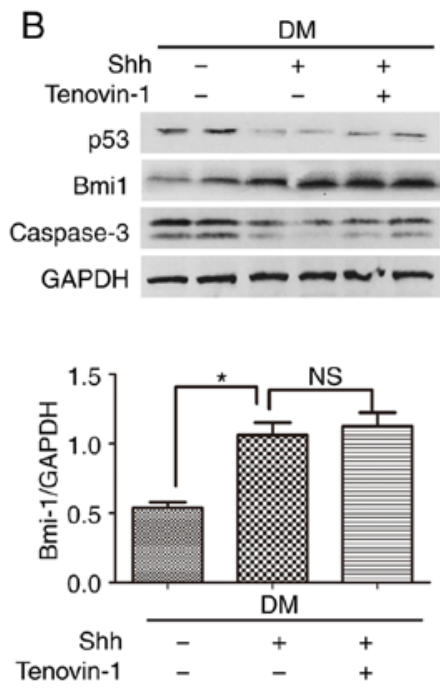
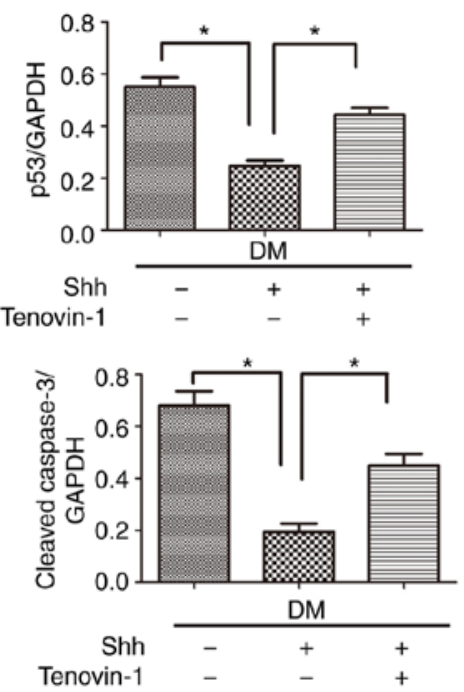
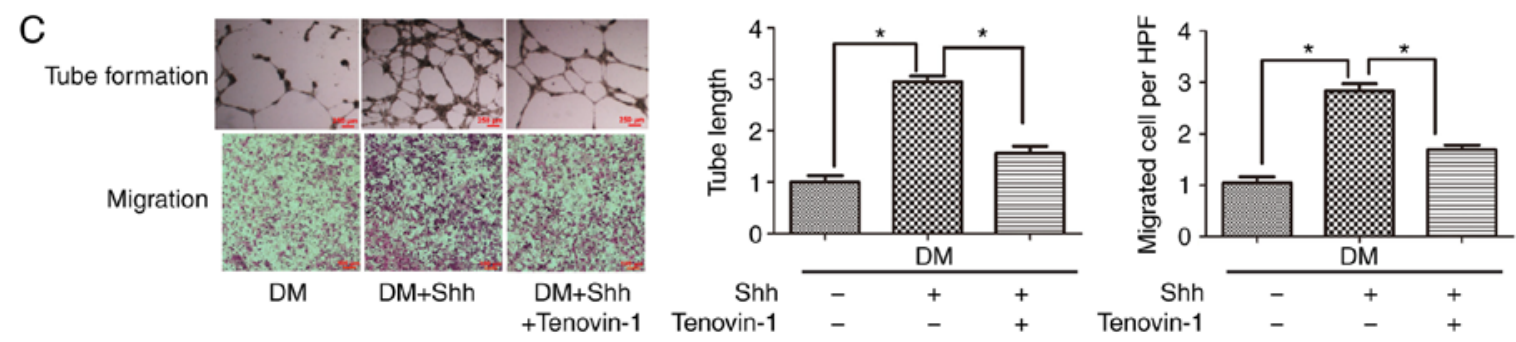

Figure 6. P53 mediates the role of the Shh/Bmil axis in diabetic EPCs. The 7 day-cultured diabetic EPCs were stimulated with the Shh protein $(0.5 \mu \mathrm{g} / \mathrm{ml})$, with or without the p53 agonist Tenovin-1 $(10 \mu \mathrm{M})$ for $24 \mathrm{~h}$. (A) Western blot analysis of p53 expression levels in control and diabetic EPCs. (B) Western blot analysis of p53, Bmi-1 and cleaved caspase-3 expression levels in diabetic EPCs. (C) EPC function was examined by cell migration and tube formation assays. Three independent experiments were performed. Values are presented as means \pm standard error of the mean. "P $\leq 0.05$, with comparisons indicated by brackets. Shh, sonic hedgehog; Bmil, BMI1 proto-oncogene; EPCs, endothelial progenitor cells; DM, diabetes mellitus; NS, not significant.

adenovirus for 2 days. First, the expression of the proapoptotic cleaved caspase-3 was investigated in the Shh-modified diabetic EPCs. The results demonstrated that Shh overexpression significantly reduced the cleaved caspase- 3 expression levels in the diabetic EPCs under normal or hypoxic conditions
(Fig. 7B). Second, the function of the Shh-modified diabetic EPCs was evaluated. As shown in Fig. 7C, Shh overexpression significantly increased the tube length and cell migration in the diabetic EPCs. These results confirmed the enhanced capabilities of the diabetic EPCs following Shh gene modification. 
A
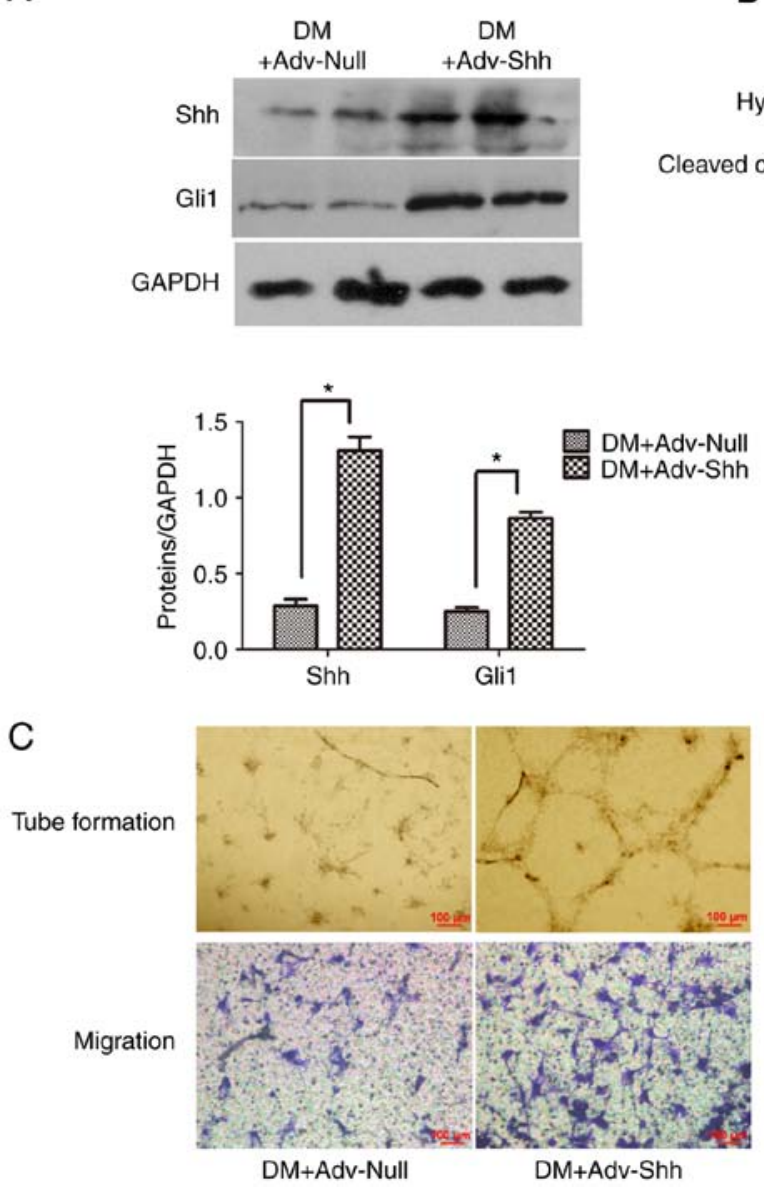

B

\begin{tabular}{|c|c|c|c|c|c|c|}
\hline \multirow[b]{2}{*}{ Adv-Null } & \multirow{2}{*}{$\begin{array}{c}\text { Control } \\
+\end{array}$} & \multicolumn{2}{|c|}{ DM } & \multirow{2}{*}{$\begin{array}{c}\text { Control } \\
+\end{array}$} & \multicolumn{2}{|c|}{ DM } \\
\hline & & + & - & & + & - \\
\hline Adv-Shh & - & - & + & - & - & + \\
\hline ooxia $12 \mathrm{~h}$ & - & - & - & + & + & + \\
\hline
\end{tabular}

Cleaved caspase-3

GAPDH
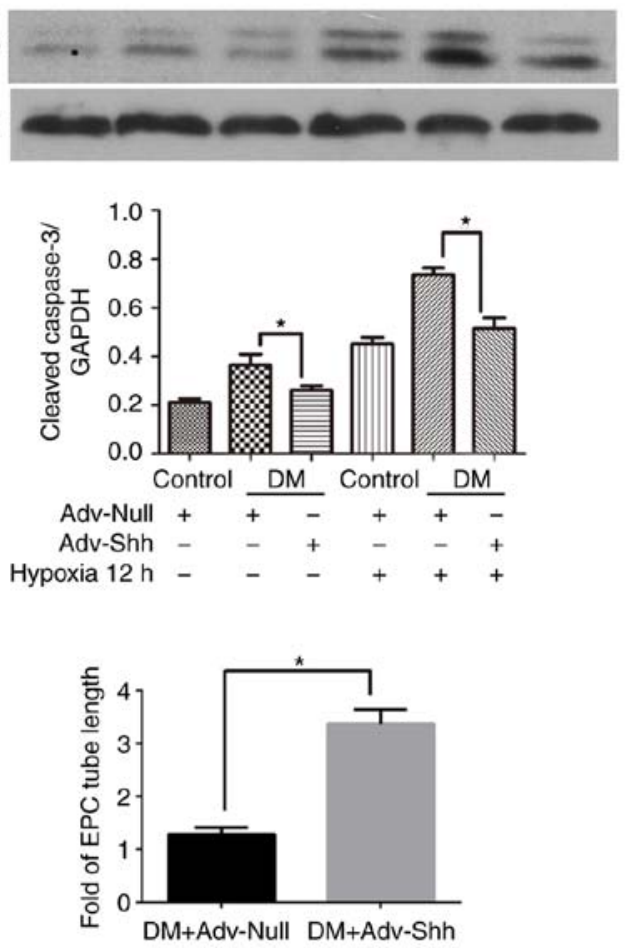

Figure 7. Gene modification of diabetic EPCs by adenovirus delivery. Shh-expressing adenovirus (Adv-Shh) or control adenovirus (Adv-Null) was used to infect the 7 day-cultured EPCs. After $48 \mathrm{~h}$ of infection, the cells were incubated in hypoxic conditions for $12 \mathrm{~h}$. (A) Western blot analysis of Shh and Gli1, and of (B) cleaved caspase-3 expression levels. (C) EPC function was examined by cell migration and tube formation assays. Three independent experiments were performed. Values are presented as means \pm standard error of the mean. ${ }^{*} \mathrm{P} \leq 0.05$, with comparisons indicated by brackets. EPCs, endothelial progenitor cells; Shh, sonic hedgehog; Gli1, GLI family zinc finger 1; DM, diabetes mellitus; Adv, adenovirus.

Injection of diabetic EPC ${ }^{\text {Shh }}$ preserves cardiac function and alleviates cardiac remodeling in DMI mice. To determine whether this endogenous impairment of the Shh pathway in diabetic EPCs may be associated with DMI and whether Shh gene therapy could improve the in vivo angiogenic capability of diabetic EPCs and enhance the cardiac function in DMI, Shh gene therapy was performed ex vivo on diabetic EPCs (DM-EPC ${ }^{\text {Shh }}$ ) prior to transplantation. Control adenovirus was transfected to diabetic EPCs $\left(\mathrm{DM}-\mathrm{EPC}^{\mathrm{Null}}\right)$ or normal EPCs $\left(\mathrm{CON}-\mathrm{EPC}^{\text {Null }}\right)$, and a vehicle PBS injection group served as control.

After 14 days of MI, injection of $2 \times 10^{5} \mathrm{CON}_{-\mathrm{EPC}}{ }^{\text {Null }}$ robustly improved the EF and FS values and decreased systolic and diastolic ventricular dilation (Fig. 8A). By contrast, injection of equal numbers of DM-EPC ${ }^{\text {Null }}$ showed no significant functional changes (Fig. 8A). When injected with equal numbers of DM-EPC ${ }^{\text {Shh }}$, the diabetic heart with MI exhibited functional benefit over DM-EPC ${ }^{\text {Null }}$. The improvements between CON-EPC ${ }^{\text {Null }}$ and DM-EPC ${ }^{\text {Shh }}$ groups had no significant difference (Fig. 8A).

At the end of the experiment, 2 weeks after MI, the hearts

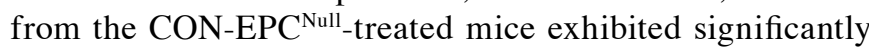
reduced infarct dimensions and border zone interstitial fibrosis compared with those from the PBS group (Fig. 8B). By contrast, equal numbers of DM-EPC ${ }^{\text {Null }}$ induced no significant changes (Fig. 8 B). The diabetic heart with MI showed less infarct size and fibrosis following treatment with DM-EPC ${ }^{\text {Shh }}$ compared with treatment with DM-EPC ${ }^{\text {Null }}$ (Fig. 8B). The improvements between CON-EPC ${ }^{\text {Null }}$ and DM-EPC ${ }^{\text {Shh }}$ groups had no significant difference (Fig. 8A).

Using CD31 staining, the capillary density was evaluated within the infarct border zone of all the hearts. The density of capillaries within the border zone was significantly higher in the hearts of the mice treated with CON-EPC ${ }^{\text {Null }}$ compared with those of the control groups (Fig. 8C). Equal numbers of DM-EPC Null induced no therapeutic change (Fig. 8C). The diabetic heart with MI showed more capillary vessels in the border zone following treatment with DM-EPC ${ }^{\text {Shh }}$ compared with treatment with DM-EPC Null (Fig. 8C). Ina ddition, the improvements between CON-EPC ${ }^{\text {Null }}$ and DM-EPC ${ }^{\text {Shh }}$ groups were not significantly different (Fig. 8C).

The present results suggested that the impaired Shh pathway in diabetic EPCs resulted in poor repair in diabetic myocardial ischemia $\left(\mathrm{CON}-\mathrm{EPC}^{\text {Null }}\right.$ vs. DM-EPC ${ }^{\text {Null }}$; CON-EPC ${ }^{\text {Null }}$ vs. DM-EPC $\left.{ }^{\text {Shh }}\right)$. However, activation of the Shh pathway via gene modification greatly accelerated EPC-mediated capillary development, thereby reducing myocardial fibrosis and enhancing the cardiac function of diabetic MI (DM-EPC ${ }^{\text {Shh }}$ vs. DM-EPC ${ }^{\text {Null }}$. 
A

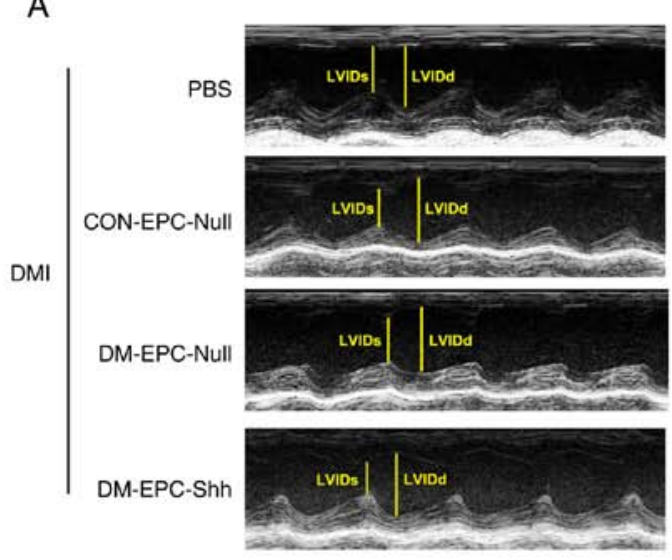

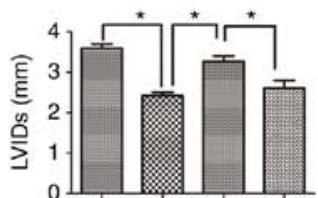

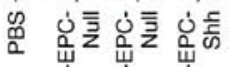

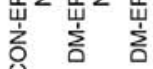

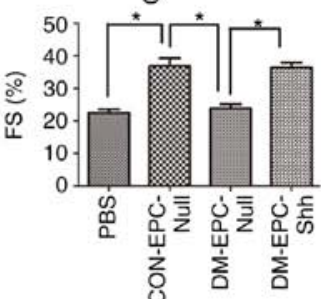

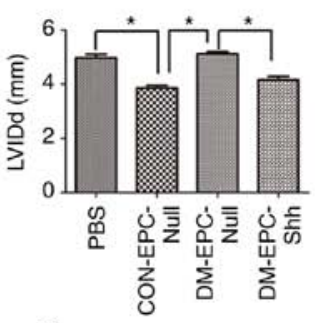

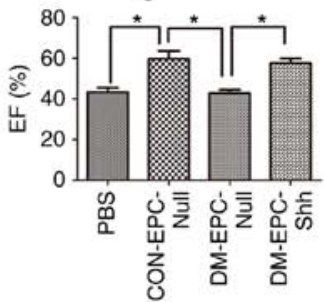

B
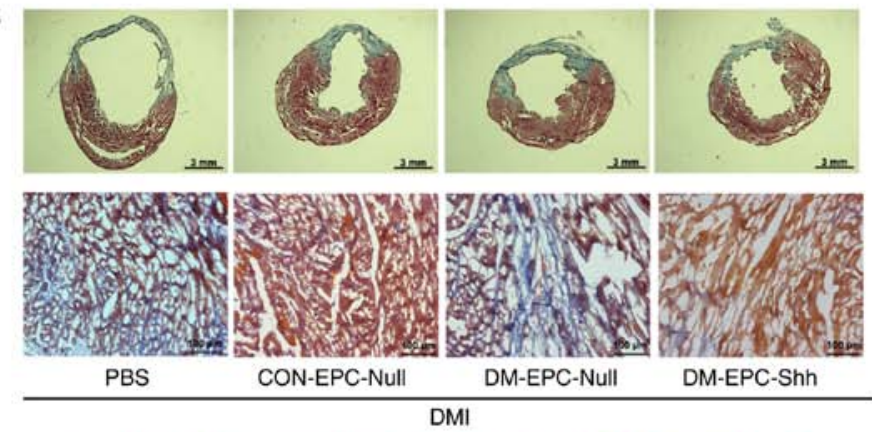

DM

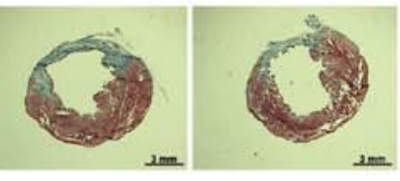

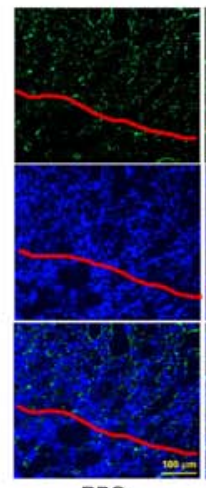

PBS

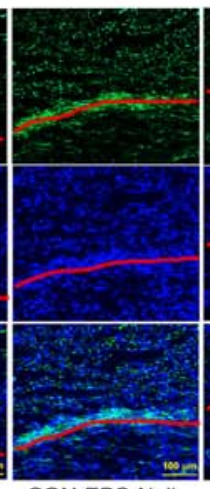

CON-EPC-Null

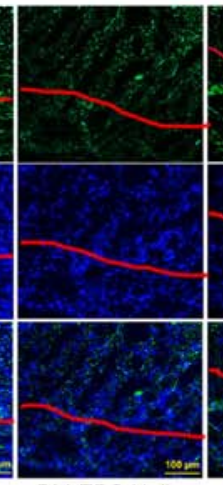

MI
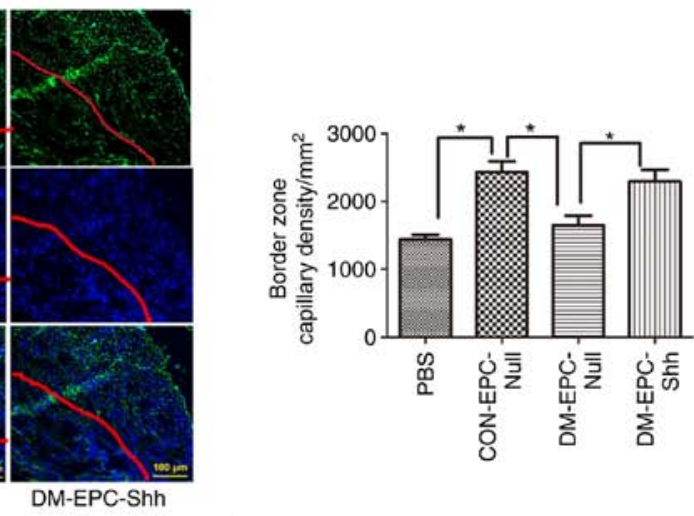

Figure 8. Injection of diabetic EPC ${ }^{\text {Shh }}$ preserves cardiac function and alleviates cardiac remodeling in DMI mice. EPCs $\left(2 \times 10^{5}\right.$ per heart) were injected immediately after coronary artery ligation. Echocardiography, Masson's trichrome staining, and CD31 detection were implemented after 2 weeks. (A) Representative M-mode images and quantitative analysis of LVIDs, LVIDd, FS and EF alues ( $\mathrm{n}=5$ ). (B) Representative images of Masson's trichrome staining (the whole frozen section and the border zone of myocardial infarction) and quantitative analysis of fibrosis ratio $(n=5)$. (C) Representative images of capillary vessels (CD31-positive cells; green). Nuclei were counterstained with DAPI (blue). The zone under the red line is the infarct area, while the upper zone is the border area. Quantitative analysis is also shown of the capillary density in the border zone of the infarcted myocardium (n=5). Values are presented as means \pm standard error of the mean. "P $\leq 0.05$, with comparisons indicated by brackets. DMI, diabetic myocardial infarction; EPCs, endothelial progenitor cells; LVIDd, LV end-diastolic dimension; LVIDs, LV end-systolic dimension; FS, fractional shortening; EF, ejection fraction; CON-EPC-Null, control EPCs modified by control adenovirus; DM-EPC-Null, diabetic EPCs modified by control adenovirus; DM-EPC-Shh, diabetic EPCs modified by Shh-overexpressing adenovirus.

Injection of diabetic EPC ${ }^{\text {Shh }}$ exhibits enhanced EPC retention and cell apoptosis in DMI mice. Next, the retention of EPCs after their transplantation in the ischemic myocardium (3 days post-MI) was investigated, by assessing the number of CM-Dil (red)-labeled EPCs in the myocardium. As shown in Fig. 9A, the retention of labeled EPCs in the myocardium was higher in the mice receiving $\mathrm{CON}-\mathrm{EPC}^{\text {Null }}$ compared with those receiving DM-EPC ${ }^{\text {Null }}$, and the delivery with DM-EPC ${ }^{\text {Shh }}$ significantly compensated for the deficiency of DM-EPC ${ }^{\text {Null }}$ retention. In addition, DM-EPC ${ }^{\text {Shh }}$ greatly reduced the apoptosis of cells in the injured myocardium, similar to the CON-EPC Null administration (Fig. 9B). By contrast, DM-EPC ${ }^{\text {Null }}$ induced no change in myocardial apoptosis (Fig. 9B). These data suggested that Shh-modified diabetic EPCs exhibited higher retention capability in the myocardial tissue, which may be an indispensable property for improved repair function.

\section{Discussion}

The predominant findings in the present study were as follows (Fig. 10): i) the Shh pathway alleviated the apoptosis of diabetic EPCs under baseline or hypoxic conditions; ii) Bmil, found in 
A

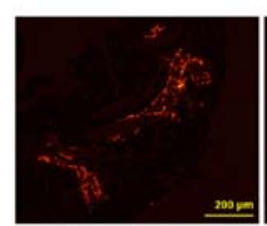

CON-EPC-Null

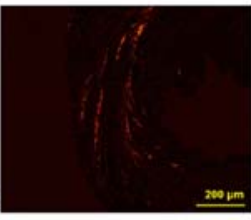

DM-EPC-Null

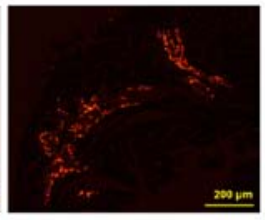

DM-EPC-Shh

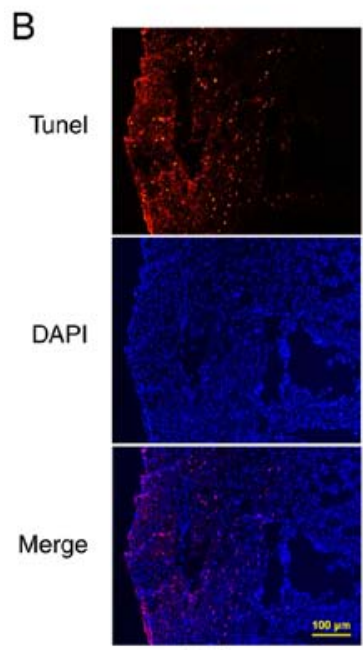

PBS

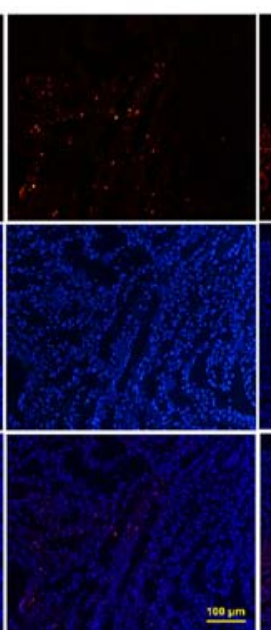

CON-EPC-Null
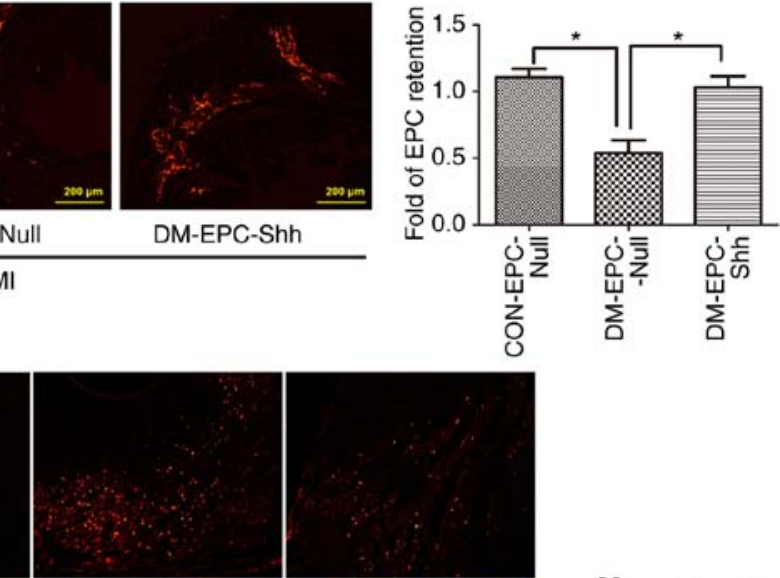

它辤
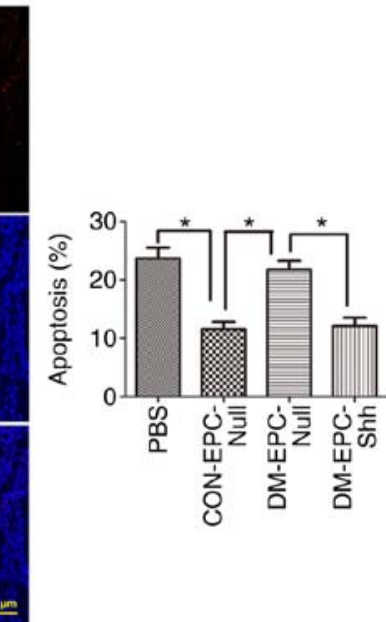

Figure 9. Diabetic EPC ${ }^{\text {Shh }}$ exhibit enhanced EPC retention and reduced cell apoptosis in DMI mice. EPCs $\left(2 \times 10^{5}\right.$ per heart) were injected immediately after coronary artery ligation, and EPC retention and cell apoptosis were examined after 3 days. (A) Representative images of CM-Dil-stained EPCs in the heart and quantitative analysis of the fluorescence density of EPC retention $(n=5)$. (B) Representative images of TUNEL staining (red) in heart tissues. Nuclei were counterstained with DAPI (blue). Quantitative analysis is also shown of the apoptotic cells in the whole infarcted myocardium (n=5). Values are presented as means \pm standard error of the mean. ${ }^{*} \mathrm{P} \leq 0.05$, with comparisons indicated by brackets. EPC, endothelial progenitor cell; DMI, diabetic myocardial infarction; CON-EPC-Null, control EPCs modified by control adenovirus; DM-EPC-Null, diabetic EPCs modified by control adenovirus; DM-EPC-Shh, diabetic EPCs modified by Shh-overexpressing adenovirus.

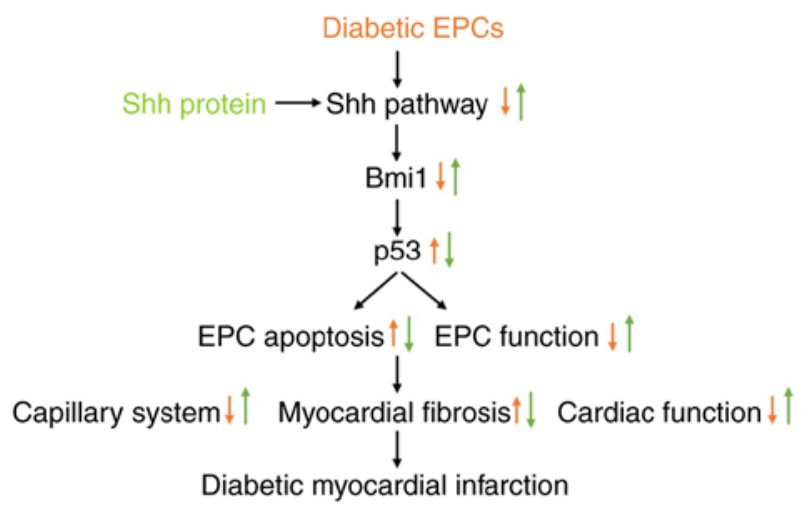

Figure 10. A schematic diagram illustrating the proposed mechanism. Orange arrows indicate the endogenous status; diabetic EPCs have an impaired Shh/Bmi1/p53 axis, which induces EPC apoptosis and dysfunction, results in decreased capillary system, increased myocardial fibrosis and worse cardiac function in diabetic myocardial infarction. Green arrows indicate the potential therapeutic role of the Shh protein, which reverses the impaired Shh/Bmil/p53 in diabetic EPCs and eventually ameliorates the status of diabetic myocardial infarction. EPCs, endothelial progenitor cells; Shh, sonic hedgehog; Bmi1, BMI1 proto-oncogene.

the present study for the first time to be related to EPCs, mediated the benefits of the Shh pathway by inhibiting p53; and iii) Shh gene therapy of diabetic EPCs rescued the myocardial repair of diabetic mice through enhanced angiogenesis and reduced apoptosis.

Patients with type 1 or type 2 diabetes mellitus have decreased numbers and impaired angiogenic function of EPCs, which have a causative role in the development and progression of virtually all diabetic cardiovascular complications, such as diabetic cardiomyopathy and diabetes combined with MI $(25,26)$. Despite evidence indicating that local or systematic administration of EPCs can significantly improve angiogenesis in injured myocardium, MI in diabetic background remains an important clinical problem leading to poor prognosis and mortality, due to the impaired function and survival of autologous EPCs (27).

The Shh pathway enhances the angiogenic function of EPCs under normal and diabetic conditions $(15,28,29)$. This effect was also confirmed in the present study, which demonstrated that delivery of the Shh gene significantly improved the migration and tube formation of diabetic EPCs. Furthermore, the present results demonstrated that stimulation with the Shh protein significantly alleviated the apoptosis of diabetic EPCs under normal and hypoxic conditions. The evidence of resistance to hypoxic conditions may be useful in coping with the inefficiency of clinical EPC injection to injured myocardium.

The present study also found that cleaved-caspase-3 levels and TUNEL-positive cells were increased by hypoxia in 
control conditions, despite the Shh pathway being activated. This effect seems to be contradictory to the protective role of Shh pathway. Actually, this stimulation of the Shh pathway is a stress-induced reaction, which is insufficient to counteract the damage induced by hypoxia. Previous studies have reported that Shh is stimulated under stress conditions, such as hypoxia and ischemia, when stress-induced injury occurs $(30,13)$. Inhibition of this stress-induced Shh expression exacerbates the damage, implying that the upregulated Shh pathway induced by stress has a protective role in alleviating cell damage (13). Furthermore, delivery of exogenous Shh protein reduces the damage, which in turn reveals the protective role of Shh pathway (30-33).

In the present study, the Shh pathway was demonstrated to be stimulated in the control EPCs following hypoxia, which is consistent with previous reports (34-37). This effect can be explained by previous literature: Hypoxia-inducible factor-1 (HIF-1), a transcriptional regulator of the Shh gene, is upregulated and then activates the Shh pathway under cell hypoxia and stress (38). However, the present results found that the Shh pathway was not activated in the diabetic EPCs; the unresponsiveness may be related to the impaired Shh pathway itself and/or potential impaired upstream factors (such as HIF-1 or nitric oxide) under diabetic conditions $(13,39,40)$.

The Shh pathway improved the function and apoptosis of EPCs in diabetic EPCs, but its downstream signaling remains elusive. Bmil is important for the self-renewal of stem cells. Bmil modulates mitochondrial function (41), ROS generation, and DNA double-strand break repair (42), and regulates the function and apoptosis of various types of cells, such as stem cells and cancer cells $(43,44)$. Therefore, the present study examined whether Shh pathway activation regulates Bmil in diabetic EPCs. The present data indicated that Bmil was significantly reduced in diabetic EPCs and that stimulation with the Shh protein efficiently reversed this reduction. In addition, Bmil silencing reversed the protection of the Shh pathway in diabetic EPC function and apoptosis. Bmil silencing also affected the function and apoptosis of normal EPCs. The present study is the first to uncover the relationship of Shh and Bmil in diabetic EPCs; impaired Shh/Bmil axis mediated the damaged status in diabetic EPCs, and maintained the status of normal EPCs. The present study is also the first to elucidate the function of Bmil in EPCs and its role as a potential target in EPC therapy.

The most known downstream factor of Bmil is p53, which is downregulated by Bmil through the negative regulation of the INK4A/ARF/p19/p14 pathway $(45,46)$. In EPCs, p53 is associated with diabetic EPC apoptosis, and the delivery of p53-silenced EPCs significantly improves ischemia in diabetic peripheral vascular disease (47). The present study revealed that the Shh pathway activation reduced p53 expression, and this effect was reversed by Bmil silencing. Accumulating p53 by Tenovin-1 reversed the benefits induced by Shh stimulation in the function and apoptosis of diabetic EPCs. This effect was similar to that observed following of Bmil-siRNA. These results suggested that p53 downregulation mediated the protection of Shh/Bmil axis activation in diabetic EPCs.

Diabetes-induced oxidative stress is well documented in the pathophysiology of diabetic complications (48). Suppression of the Shh pathway resulting from oxidative stress, which has been reported in BM stromal cells in vitro $(49,50)$, was confirmed in the diabetic EPCs in the present study. The results suggested that the diabetic EPCs had a higher ROS level (DHE dye) compared with control EPCs, and delivery of the antioxidant Tempol significantly reduced the ROS level and restored the impaired Shh pathway in the diabetic EPCs. (Fig. S2) These results indicated that oxidative stress may be involved in the impaired Shh pathway of diabetic EPCs.

The present study demonstrated that the Shh gene-modified diabetic EPCs exhibited significantly improved cardiac function compared with the untreated diabetic EPCs. In addition, treatment with DM-EPC ${ }^{\text {shh }}$ robustly increased the capillary development within the infarct border zone, accompanied by reduced infarct sizes and interstitial fibrosis. The indicated mechanism, i.e. autocrine secretion of the angiogenic factor Shh by engineered EPCs, may be involved; however, other hypotheses cannot be excluded. Modified EPCs themselves may respond better to angiogenic or noxious stimuli (such as oxidative stress at reperfusion) from the microenvironment, which might also contribute to their improved function.

In addition to the long-term effects of Shh-modified DM-EPCs, the present results also demonstrated improved cell retention of these cells and myocardial apoptosis, which may be involved in the protection of DM-EPC ${ }^{\text {Shh }}$ in diabetic MI. It was assumed that the autocrine Shh signaling may increase the retention numbers of DM-EPC ${ }^{\text {shh }}$ and a paracrine loop with the myocardial cells may alleviate their apoptosis on day 3 after cardiac ischemia. Further analysis of the secretome of Shh-modified EPCs and further experiments, such as investigations of cell-cell interactions, are needed to investigate these mechanisms in depth. Indeed, normal EPCs can repair the ischemic myocardium through angiogenesis and paracrine signaling, thus restoring blood supply and salvaging cells, and eventually improving cardiac function $(19,51)$; these effects are consistent with the effects of CON-EPC ${ }^{\text {Null }}$ presented in the current study. In addition, the effectiveness of repair is related to the numbers of EPCs. For example, $2 \times 10^{6}$ EPCs are more effective than $1 \times 10^{6}$ EPCs in wound healing (17). In the present study, $2 \times 10^{5}$ EPCs were used, as described in previous reports $(19,52)$. The status of EPCs is also related to repair effectiveness. Diseases, such as hypertension and diabetes, significantly damage the function and numbers of EPCs and influence their repair potential (53), which is consistent with the present results of the DM-EPC Null.

In the present study, the relationship between the impaired Shh pathway of diabetic EPCs and diabetic myocardium was elucidated. Treatment with diabetic EPCs did not significantly change the status of diabetic myocardium with ischemia. This was greatly improved by diabetic EPCs harboring a Shh gene modification, to a level similar to normal EPCs. These findings indicated that the impaired Shh pathway undermined the behavior of diabetic EPCs in injured diabetic myocardium, leading to deteriorated myocardial repair, suggesting poor prognosis and eventually high mortalities in diabetic MI. Amending this pathway in diabetic EPCs may remarkably improve the potential of autologous EPC therapy in diabetic MI.

In conclusion, the enhanced Shh pathway in diabetic EPCs improved their angiogenic function and survival through Bmil upregulation and p53 downregulation, and consequently 
rescued the inefficient repair in diabetic myocardium under ischemia. For the development of improved autologous cell therapies for patients with diabetes, alterations in the progenitor cells through gene therapy prior to transplantation may be necessary to compensate for their defective viability and function.

\section{Acknowledgements}

The authors thank Professor Gui-Ping Zhang (Department of Pharmacology, Guangzhou Medical University) for his valuable advice regarding methods in this manuscript.

\section{Funding}

This study was supported by the National Natural Science Foundation of China (grant no. 81302767 to Dr Qing Xiao, and grant no. 81573433 to Dr Jian-Dong Luo), the Science and Technology Planning Project of Guangdong Province (grant nos. 2014A020212361 and 2017A020215194 to Dr Qing Xiao), the Medical Scientific Research Foundation of Guangdong Province (grant no. A2015444 to Dr Qing Xiao, and grant no. B2018054 to Dr Xiao-Ling Zhang), the Natural Science Foundation of Guangzhou (grant no. 2016A030310271 to Dr Yuan Qin), the Scientific and Technological Planning Program of Guangzhou (grant no. 2017071010458 to Dr Ying-Hua Liu), and the Municipal Education Bureau Program of Guangzhou (grant no. 1201610286 to Dr Ying-Hua Liu).

\section{Availability of data and materials}

The datasets used or analyzed during the current study are available from the corresponding author on reasonable request.

\section{Authors' contributions}

QX contributed to conception and design, provision of study material, collection and/or assembly of data, data analysis and interpretation, manuscript writing, and final approval of the manuscript. XYZ, RCJ, XHC, XZ, KFC and SYC contributed to collection and/or assembly of data, and final approval of the manuscript. XLZ, YQ and YHL contributed to provision of study material and final approval of the manuscript. JDL contributed to conception and design, financial support, administrative support, provision of study material, data analysis and interpretation, manuscript writing, and final approval of manuscript.

\section{Ethics approval and consent to participate}

All experimental protocols involving animals were approved by the Animal Care and Welfare Committee of Guangzhou Medical University.

\section{Patient consent for publication}

Not applicable.

\section{Competing interests}

The authors declare that they have no competing interest

\section{References}

1. Patel NB and Balady GJ: Diagnostic and prognostic testing to evaluate coronary artery disease in patients with diabetes mellitus. Rev Endocr Metab Disord 11: 11-20, 2010.

2. Cheng R and Ma J: Angiogenesis in diabetes and obesity. Rev Endocr Metab Disord 16: 67-75, 2015.

3. Howangyin KY and Silvestre JS: Diabetes mellitus and ischemic diseases: Molecular mechanisms of vascular repair dysfunction. Arterioscler Thromb Vasc Biol 34: 1126-1135, 2014.

4. Co M, Tay E, Lee CH, Poh KK, Low A, Lim J, Lim IH, Lim YT and Tan HC: Use of endothelial progenitor cell capture stent (Genous Bio-Engineered R Stent) during primary percutaneous coronary intervention in acute myocardial infarction: Intermediate- to long-term clinical follow-up. Am Heart J 155: 128-132, 2008.

5. Zhu J, Song J, Yu L, Zheng H, Zhou B, Weng S and Fu G: Safety and efficacy of autologous thymosin $\beta 4$ pre-treated endothelial progenitor cell transplantation in patients with acute ST segment elevation myocardial infarction: A pilot study. Cytotherapy 18: 1037-1042, 2016.

6. Georgescu A, Alexandru N, Constantinescu A, Titorencu I and Popov D: The promise of EPC-based therapies on vascular dysfunction in diabetes. Eur J Pharmacol 669: 1-6, 2011.

7. Ling L, Shen Y, Wang K, Jiang C, Fang C, Ferro A, Kang L and $\mathrm{Xu} \mathrm{B}$ : Worse clinical outcomes in acute myocardial infarction patients with type 2 diabetes mellitus: Relevance to impaired endothelial progenitor cells mobilization. PLoS One 7: e50739, 2012.

8. António N, Fernandes R, Ribeiro CF and Providência LA: Challenges in vascular repair by endothelial progenitor cells in diabetic patients. Cardiovasc Hematol Disord Drug Targets 10: 161-166, 2010.

9. Briscoe J and Thérond PP: The mechanisms of Hedgehog signalling and its roles in development and disease. Nat Rev Mol Cell Biol 14: 416-429, 2013.

10. Alvarez-Buylla A and Ihrie RA: Sonic hedgehog signaling in the postnatal brain. Semin Cell Dev Biol 33: 105-111, 2014.

11. Lopez-Rios J: The many lives of SHH in limb development and evolution. Semin Cell Dev Biol 49: 116-124, 2016.

12. Rimkus TK, Carpenter RL, Qasem S, Chan M and Lo HW: Targeting the sonic hedgehog signaling pathway: Review of smoothened and gli inhibitors. Cancers (Basel) 8: E22, 2016.

13. Xiao Q, Hou N, Wang YP, He LS, He YH, Zhang GP, Yi Q, Liu SM, Chen MS and Luo JD: Impaired sonic hedgehog pathway contributes to cardiac dysfunction in type 1 diabetic mice with myocardial infarction. Cardiovasc Res 95: 507-516, 2012.

14. Xiao Q, Yang YA, Zhao XY, He LS, Qin Y, He YH, Zhang GP and Luo JD: Oxidative stress contributes to the impaired sonic hedgehog pathway in type 1 diabetic mice with myocardial infarction. Exp Ther Med 10: 1750-1758, 2015.

15. Qin Y, He YH, Hou N, Zhang GS, Cai Y, Zhang GP, Xiao Q, He LS, Li SJ, Yi Q and Luo JD: Sonic hedgehog improves ischemia-induced neovascularization by enhancing endothelial progenitor cell function in type 1 diabetes. Mol Cell Endocrinol 423: 30-39, 2016.

16. Liu Y, Gao M, Ma MM, Tang YB, Zhou JG, Wang GL, Du YH and Guan YY: Endophilin A2 protects $\mathrm{H} 2 \mathrm{O} 2$-induced apoptosis by blockade of Bax translocation in rat basilar artery smooth muscle cells. J Mol Cell Cardiol 92: 122-133, 2016.

17. Marrotte EJ, Chen DD, Hakim JS and Chen AF: Manganese superoxide dismutase expression in endothelial progenitor cells accelerates wound healing in diabetic mice. J Clin Invest 120: 4207-4219, 2010.

18. Krishnamurthy P, Thal M, Verma S, Hoxha E, Lambers E, Ramirez V, Qin G, Losordo D and Kishore R: IL-10 deficiency impairs bone marrow-derived endothelial progenitor cell (EPC) survival and function in ischemic myocardium. Circ Res 109: 1280-1289, 2011.

19. Sun YY, Bai WW, Wang B, Lu XT, Xing YF, Cheng W, Liu XQ and Zhao YX: Period 2 is essential to maintain early endothelial progenitor cell function in vitro and angiogenesis after myocardial infarction in mice. J Cell Mol Med 18: 907-918, 2014.

20. Zhang H, He Y, Zhang G, Li X, Yan S, Hou N, Xiao Q, Huang Y, Luo M, Zhang G, et al: HDAC2 is required by the physiological concentration of glucocorticoid to inhibit inflammation in cardiac fibroblasts. Can J Physiol Pharmacol 95: 1030-1038, 2017.

21. Cao L, Bombard J, Cintron K, Sheedy J, Weetall ML and Davis TW: BMI1 as a novel target for drug discovery in cancer. J Cell Biochem 112: 2729-2741, 2011. 
22. Shahi MH, Farheen S, Mariyath MP and Castresana JS: Potential role of Shh-Gli1-BMI1 signaling pathway nexus in glioma chemoresistance. Tumour Biol 37: 15107-15114, 2016.

23. Wang $X$, Venugopal C, Manoranjan B, McFarlane N, O'Farrell E, Nolte S, Gunnarsson T, Hollenberg R, Kwiecien J, Northcott P, et al: Sonic hedgehog regulates Bmil in human medulloblastoma brain tumor-initiating cells. Oncogene 31: 187-199, 2012.

24. Subkhankulova T, Zhang X, Leung C and Marino S: Bmi1 directly represses p21Waf1/Cip1 in Shh-induced proliferation of cerebellar granule cell progenitors. Mol Cell Neurosci 45: $151-162,2010$.

25. Savvatis K, Westermann D, Schultheiss HP and Tschöpe C: Kinins in cardiac inflammation and regeneration: Insights from ischemic and diabetic cardiomyopathy. Neuropeptides 44 $119-125,2010$

26. Aragona CO, Imbalzano E, Mamone F, Cairo V, Lo Gullo A, D'Ascola A, Sardo MA, Scuruchi M, Basile G, Saitta A and Mandraffino G: Endothelial progenitor cells for diagnosis and prognosis in cardiovascular disease. Stem Cells Int 2016 : 8043792,2016

27. António N, Fernandes R, Soares A, Soares F, Lopes A Carvalheiro T, Paiva A, Pêgo GM, Providência LA, Gonçalves L and Ribeiro CF: Reduced levels of circulating endothelial progenitor cells in acute myocardial infarction patients with diabetes or pre-diabetes: Accompanying the glycemic continuum. Cardiovasc Diabetol 13: 101, 2014.

28. Fu JR, Liu WL, Zhou JF, Sun HY, Xu HZ, Luo L, Zhang H and Zhou YF: Sonic hedgehog protein promotes bone marrow-derived endothelial progenitor cell proliferation, migration and VEGF production via PI 3-kinase/Akt signaling pathways. Acta Pharmacol Sin 27: 685-693, 2006.

29. Kanaya K, Ii M, Okazaki T, Nakamura T, Horii-Komatsu M, Alev C, Akimaru H, Kawamoto A, Akashi H, Tanaka H, et al: Sonic Hedgehog signaling regulates vascular differentiation and function in human CD34 positive cells: Vasculogenic CD34(+) cells with Sonic Hedgehog. Stem Cell Res 14: 165-176, 2015.

30. Kusano KF, Pola RT, Murayama T, Curry C, Kawamoto A Iwakura A, Shintani S, Ii M, Asai J, Tkebuchava T, et al: Sonic hedgehog myocardial gene therapy: Tissue repair through transient reconstitution of embryonic signaling. Nat Med 11: 1197-1204, 2005.

31. Ahmed RP, Haider KH, Shujia J, Afzal MR and Ashraf M: Sonic Hedgehog gene delivery to the rodent heart promotes angiogenesis via iNOS/netrin-1/PKC pathway. PLoS One 5: e8576, 2010

32. Xiao Q, Yang Y, Qin Y, He YH, Chen KX, Zhu JW, Zhang GP and Luo JD: AMP-activated protein kinase-dependent autophagy mediated the protective effect of sonic hedgehog pathway on oxygen glucose deprivation-induced injury of cardiomyocytes. Biochem Biophys Res Commun 457: 419-425, 2015.

33. Roncalli J, Renault MA, Tongers J, Misener S, Thorne T, Kamide C, Jujo K, Tanaka T, Ii M, Klyachko E and Losordo DW: Sonic hedgehog-induced functional recovery after myocardial infarction is enhanced by AMD3100-mediated progenitor-cell mobilization. J Am Coll Cardiol 57: 2444-2452, 2011

34. Liu Z, Tu K, Wang Y, Yao B, Li Q, Wang L, Dou C, Liu Q and Zheng X: Hypoxia accelerates aggressiveness of hepatocellular carcinoma cells involving oxidative stress, epithelial-mesenchymal transition and non-canonical hedgehog signaling. Cell Physiol Biochem 44: 1856-1868, 2017.

35. Hung YH, Chang SH, Huang CT, Yin JH, Hwang CS, Yang LY and Yang DI: Inhibitor of differentiation-1 and hypoxia-inducible factor-1 mediate sonic hedgehog induction by amyloid beta-peptide in rat cortical neurons. Mol Neurobiol 53: 793-809, 2016.

36. Spivak-Kroizman TR, Hostetter G, Posner R, Aziz M, Hu C, Demeure MJ, Von Hoff D, Hingorani SR, Palculict TB, Izzo J, et al: Hypoxia triggers hedgehog-mediated tumor-stromal interactions in pancreatic cancer. Cancer Res 73: 3235-3247, 2013.
37. Onishi H, Kai M, Odate S, Iwasaki H, Morifuji Y, Ogino T, Morisaki T, Nakashima Y and Katano M: Hypoxia activates the hedgehog signaling pathway in a ligand-independent manner by upregulation of Smo transcription in pancreatic cancer. Cancer Sci 102: 1144-1150, 2011

38. Bijlsma MF, Groot AP, Oduro JP, Franken RJ, Schoenmakers SH, Peppelenbosch MP and Spek CA: Hypoxia induces a hedgehog response mediated by HIF-1alpha. J Cell Mol Med 13: 2053-2060, 2009.

39. Marfella R, D'Amico M, Di Filippo C, Piegari E, Nappo F, Esposito K, Berrino L, Rossi F and Giugliano D: Myocardial infarction in diabetic rats: Role of hyperglycaemia on infarct size and early expression of hypoxia-inducible factor 1 . Diabetologia 45: 1172-1181, 2002.

40. Ceriello A, Quagliaro L, D'Amico M, Di Filippo C, Marfella R, Nappo F, Berrino L, Rossi F and Giugliano D: Acute hyperglycemia induces nitrotyrosine formation and apoptosis in perfused heart from rat. Diabetes 51: 1076-1082, 2002

41. Banerjee Mustafi S, Aznar N, Dwivedi SK, Chakraborty PK, Basak R, Mukherjee P, Ghosh P and Bhattacharya R: Mitochondrial BMI1 maintains bioenergetic homeostasis in cells. FASEB J 30: 4042-4055, 2016.

42. Lin X, Ojo D, Wei F, Wong N, Gu Y and Tang D: A novel aspect of tumorigenesis-BMI1 functions in regulating dna damage response. Biomolecules 5: 3396-3415, 2015.

43. Allegra E, Trapasso S, Pisani D and Puzzo L: The role of BMI as a biomarker of cancer stem cells in head and neck cancer: A review. Oncology 86: 199-205, 2014.

44. Ren H, Du P, Ge Z, Jin Y, Ding D, Liu X and Zou Q: TWIST1 and BMI 1 in cancer metastasis and chemoresistance. J Cancer 7: 1074-1080, 2016.

45. Yao D, Wang Y, Xue L, Wang H, Zhang J and Zhang X: Different expression pattern and significance of p14ARF-Mdm2-p53 pathway and Bmi-1 exist between gastric cardia and distal gastric adenocarcinoma. Hum Pathol 44: 844-851, 2013.

46. Xu XH, Liu Y, Li DJ, Hu J, Su J, Huang Q, Lu MQ, Yi F, Bao D and Fu YZ: Effect of shRNA-mediated gene silencing of Bmi-1 expression on chemosensitivity of CD44+ nasopharyngeal carcinoma cancer stem-like cells. Technol Cancer Res Treat 15: NP27-NP39, 2016.

47. Kundu N, Domingues CC, Chou C, Ahmadi N, Houston S, Jerry DJ and Sen S: Use of p53-silenced endothelial progenitor cells to treat ischemia in diabetic peripheral vascular disease. J Am Heart Assoc 6: e005146, 2017.

48. Brownlee M: Biochemistry and molecular cell biology of diabetic complications. Nature 414: 813-820, 2001.

49. Feldman EL: Oxidative stress and diabetic neuropathy: A new understanding of an old problem. J Clin Invest 111: 431-433, 2003.

50. Kim WK, Meliton V, Bourquard N, Hahn TJ and Parhami F: Hedgehog signaling and osteogenic differentiation in multipotent bone marrow stromal cells are inhibited by oxidative stress. J Cell Biochem 111: 1199-1209, 2010.

51. Larrick JW and Mendelsohn A: Applied healthspan engineering. Rejuvenation Res 13: 265-280, 2010.

52. Chen X, Gu M,Zhao X,Zheng X, Qin Y and You X: Deterioration of cardiac function after acute myocardial infarction is prevented by transplantation of modified endothelial progenitor cells overexpressing endothelial NO synthases. Cell Physiol Biochem 31: 355-365, 2013.

53. Bianconi V, Sahebkar A, Kovanen P, Bagaglia F, Ricciuti B, Calabrò $P$, Patti $G$ and Pirro M: Endothelial and cardiac progenitor cells for cardiovascular repair: A controversial paradigm in cell therapy. Pharmacol Ther 181: 156-168, 2017.

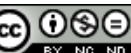

This work is licensed under a Creative Commons Attribution-NonCommercial-NoDerivatives 4.0 International (CC BY-NC-ND 4.0) License. 